\title{
Tumbas y sociedades locales en el centro de la península en la alta edad media: el caso de la comarca de Riba Côa (Portugal)*
}

\author{
Iñaki Martín Viso**
}

\begin{abstract}
RESU MEN :
Las tumbas excavadas en roca representan uno de los vestigios más abundantes de la época altomedieval. Sin embargo, su análisis, debido a la ausencia de ajuares, restos óseos y de contextos arqueológicos bien estudiados, resulta complejo. A partir del caso específico de la comarca portuguesa de Riba Côa, el trabajo plantea que estas inhumaciones estuvieron en uso entre los siglos VII a XI. Por otro lado, se matiza la afirmación de un poblamiento disperso, plasmado en tales tumbas, generalmente aisladas, y se orienta la perspectiva hacia el análisis de la ordenación del espacio local, donde se privilegia la ocupación de áreas fluviales (ribeiras). Por último, el análisis de estas sepulturas permite descubrir una sociedad campesina, donde el influjo de la Iglesia es prácticamente nulo, mientras que un factor esencial es la vinculación de las tumbas con los derechos de propiedad.
\end{abstract}

\begin{abstract}
:
The graves cut into the rock are one of the most common remains of Early Middle Ages in the Iberian Peninsula. However the analysis is so complex, due to the absence of grave-goods, skeletons and well-studied archaeological contexts. This paper is based on the Portuguese district of Riba Côa, where this kind of inhumation was used between seventh and eleventh centuries. $\mathrm{O}$ the one hand, the link of these to mbs with a dispersed settlement, thanks to the usual isolation of the graves, is doubtful; the analysis is orientated to the study of the organization of the local territories, in which there was a prior occupation of river areas (ribeiras). $0 \mathrm{n}$ the other hand, these graves seem to be created by a peasant society, without almost any ecclesiastical influence and with the connection between tombs and rights of property.
\end{abstract}

\section{INTRODUCCIÓN}

Las tumbas excavadas en la roca representan un elemento muy numeroso del paisaje arqueológico de la Península Ibérica, con hallazgos que se extienden desde Cataluña hasta Andalucía, si bien el norte cantábrico presenta escasos vestigios de este tipo de inhumación (GARCíA CAMIN 0, 2002: 410-411). Se trata, por tanto, de uno de los pocos fenómenos fechados en época altomedieval que son abundantes y fácilmente detectables, sobre todo en amplias zonas, como el centro peninsular, donde los avances sobre el conocimiento de los poblados es aún muy endeble, con la notable excepción de Madrid

\footnotetext{
* Este trabajo se integra en el proyecto de investigación HUM2006-03038, financiado por la Dirección General de Investigación, titulado El centro de la Península Ibérica entre la Antigüedad y la Edad M edia: espacios, poderes y representaciones (siglos VII-XI). Buena parte de la bibliografía se recogió en la Universidad de Coimbra, en una estancia como becario postdoctoral entre los años 2003 y 2004, donde conté siempre con la amable disposición de la profesora Ma Helena da Cruz Coelho. También quiero agradecer el apoyo prestado por el Centro de Estudos Ibéricos (Guarda, Portugal). De igual forma, he gozado de la disponibilidad y amabilidad para darme informaciones, consejos y comentarios de Juan Carlos Castillo Armenteros, Helena Catarino, Julio Escalona, Iker Gómez Tarazaga, Jorge Marques, Marcos 0 sório, Juan Antonio Q uirós, Manuel Perestrelo y Alfonso Vigil-Escalera. Por último, Iker Gómez Tarazaga, Ma Carmen Hernández Charro y Fernando Luis Corral me han acompañado en varias de mis "excursiones portuguesas" y su compañía ha hecho más grato el desarrollo de este trabajo.

** Departamento de Historia Medieval, Moderna y Contemporánea. Facultad de Geografía e Historia. Universidad de Salamanca.
} 
(VIG IL-ESCA LERA, 2006). Sin embargo, su uso en los análisis sobre este periodo ha sido hasta el momento escaso, cuando no irrelevante, a pesar de que las necrópolis se consideran en otros ámbitos un elemento de especial relevancia en el estudio sobre todo de lo social y simbólico. Al contrario de lo que sucede con las necrópolis merovingias (HALSA LL, 1995), con las mal denominadas necrópolis visigodas 0 con las halladas recientemente en los últimos tiempos en el PaísVasco - que constituyen un hito en la investigación (AZKARATE, 2001)- las tumbas excavadas en roca carecen, salvo casos excepcionales, de ajuares, de restos humanos y de contextos arqueológicos claros. N o puede obviarse la despreocupación por la arqueología que tradicionalmente ha caracterizado al medievalismo y la consideración ancilar de los periodos post-romano y altomedieval con respecto a las épocas romana y feudal. En relación con esto último, parece evidente que se produce una "invisibilidad" arqueológica general de las aristocracias altomedievales, afectadas por una disminución del papel del estado como creador y distribuidor del estatus (W ICKHAM, 2005), así como por la creciente cristianización del ritual, que favoreció las tendencias contrarias a la ostentación postmortem (LA RO CCA, 1998a).

A lo largo de estas páginas se pretende únicamente ofrecer una serie de reflexiones e hipótesis sobre determinados problemas relacionados con las tumbas excavadas en la roca, tomando como ejemplo el caso de la comarca portuguesa de Riba Côa. Ésta se encuentra situada en el extremo oriental de Portugal, en el distrito de Guarda, confinando con la frontera entre dicho país y España. Como límites de esta área se han tomado los de los actuales concelhos de Vila $\mathrm{N}$ ova de Foz Côa, Figueira de Castelo Rodrigo, Pinhel, A Imeida y Sabugal, que componen un territorio de 2732 kilómetros cuadrados. Dicho espacio, que posee enormes similitudes con la penillanura de Ciudad Rodrigo, ya en España, disfruta de una acusada personalidad, ya que el río Côa actúa como eje articulador. Se trata de un curso que nace en la sierra de Malcata para continuar en dirección sur-norte hacia el Duero, donde afluye en las cercanías de Vila $\mathrm{N}$ ova de Foz Côa. A partir de la localidad de Vale Longo, el cauce del Côa se encaja en la penillanura, separando con nitidez las dos orillas - aunque los vados y pasos son abundantes- sin que se desarrolle una franja de vega. Por esa razón, son otros cauces secundarios, las ribeiras, los que ejercen el papel de vertebradores del territo rio, ya que en ellos existen áreas aluviales. Sin embargo, poseen unos caudales sometidos a una fuerte estacionalidad, llegando a desecarse en determinadas épocas. La mayor parte del territorio corresponde al típico paisaje de penillanura, con suelos bastante ácidos y sin apenas relieves. Destacan, de todas formas, algunas elevaciones, como la Sierra de Marofa, a la altura de Castelo Rodrigo, que alcanza los 976 metros de altitud, y, más al sur, la sierra del Hombre de Piedra, asociada a la Sierra de Malcata -que marca el límite meridional de la comarca- donde se superan los 1000 metros de altitud, marcando la divisoria de aguas y la conexión con el Sistema Central ${ }^{1 .}$

Riba Côa se relaciona con el amplio conjunto de penillanuras que se extienden a uno y otro lado de la raya fronteriza, por Salamanca, Zamora y Viseu, zonas con las que comparte además una evolución semejante en época altomedieval. En tal sentido, puede verse como un ejemplo de los desarrollos que se observan en el centro de la Península lbérica, en las áreas que van desde Medinaceli hasta la sierra de la Estrella, durante este periodo. Durante los años 2004 a 2006, se ha llevado a cabo un trabajo sobre esta comarca entre los siglos $\mathrm{V}$ al XI, incluyendo la labor de localización y análisis de estas tumbas (MARTín VISO, 2005a y e.p.), que ha permitido detectar 92 sitios en los que se conocen este tipo de inhumaciones (Fig. 1 y apéndice). Tales datos componen la base empírica de nuestra explicación.

1 Para una inserción de esta comarca en el conjunto portugués, véase RIBEIRO, 1998. 


\section{LOS PROBLEMAS DE DATACIÓN}

Resulta inexcusable plantearse la cronología de estas tumbas; pero es entonces cuando se revelan los problemas que arrastra todo análisis de las mismas, ante la carencia de datos absolutos. Desde los trabajos de A. del Castillo a mediados de los años sesenta que comparaban el caso catalán con el castellano, se vienen datando estas tumbas en los siglos altomedievales, en dos fases diferenciadas: una, comenzada quizá en el VII y proseguida en los siglos VIII y IX, caracterizada por las formas no-antropomorfas, especialmente ovales y de bañera, y otra propiamente de los siglos IX y X, marcada por el antropomorfismo de las tumbas. D icho autor consideraba que estas tumbas eran el reflejo de los mozárabes que habían repoblado las tierras del valle del Duero y del Llobregat abandonadas en el VIII por sus habitantes (CAST ILLO, 1970 y 1972). Esta interpretación, que se basaba en las teorías despoblacionistas, se convirtió en el paradigma explicativo dominante (LOYO LA PEREA, 1977, AN DRIO GONZALO, 1994, PADILLA LAPUEN TE, 2002) ${ }^{2}$. Sin embargo, la investigación de las últimas décadas ha puesto en duda, cuando no ha soslayado, la explicación despoblacionista. Además la secuencia cronológica de tumbas no antropomorfas a antropomorfas se sustenta exclusivamente en criterios formales, que son de difícil aplicación cuando conviven formas muy diferentes en un mismo yacimiento (YÁÑ EZ et alii, 1994), o cuando se advierte de la superioridad generalizada de las antropoides, lo que llevaría a pensar en que no hubo enterramientos antes del siglo $X$. A lgunos investigadores han tratado de ofrecer perspectivas diferentes, matizando la oposición entre fases definidas por la ausencia o no de antropomorfismo, aunque preservando la secuenciación formalista, y subrayando el origen de estas inhumaciones en el siglo VII (BARRO CA, 1987; LÓ PEZ Q UIRO GA y RO DRÍGUEZ LOVELLE, 1992). Algunos datos procedentes de excavaciones en diversas zonas de la Península
Ibérica atestiguan la presencia de este modelo de inhumación totalmente desarrollado en época visigoda, bien porque estas tumbas fueron obliteradas por espacios hidráulicos de época islámica (JIMÉN EZ PUERTAS, 2002:118), bien por su diferenciación con respecto a otras fases de enterramiento musulmán (SERRANO PEÑ A y CASTILLO ARMENTERO S, 2000; SALVATIERRA y CASTILLO , 2000), o bien por los restos asociados a estas necrópolis (GUTIÉRREZ DOHIJO, 2001; GOMES, 2002). Por otro lado, se han podido realizar dataciones absolutas de algunos restos óseos a través de C14, que arrojan una cronología del siglo VII para espacios muy diferentes (SÁEN Z DE URTURI, 1990; GIL ZUBILLAGA y SÁEN Z DE URTURI, 2001; BEN AVENTE, PAZ y O RTIZ, 2006). Estas dataciones son habituales desde hace tiempo entre los investigadores de la zona salmantina (FABIÁN et alii, 1986) y parecen también corresponder con lo que sucede en la región de Viseu (MARQ UES, 1996 y 2000: 186 y 218). La presencia de algunos materiales decorativos procedentes de ajuares funerarios de tradición tardoantigua en determinadas necrópolis de áreas que, como Riba Côa, se insertan en el amplio conjunto del centro peninsular, como los hallados en las necrópolis de El Berrueco (El Tejado, Salamanca) ${ }^{3}$ y N uestra Señora de los Remedios (Colmenar Viejo, Madrid) (CO LMENAREJO GARCÍA, 1987: 13-17), corroborarían esa datación post quem. En cuanto al término ante quem, el hecho de que mayoritariamente estas necrópolis estén fuera de los centros de hábitat aldeanos fijados en la Plena Edad Media permite asegurar que su uso finalizó hacia los siglos XI-XII. En este final jugó un importante papel la configuración de la parroquia como eje centralizador de la actividad funeraria. En el caso del centro peninsular, la consolidación de la estructura parroquial debe relacionarse con la integración de tales espacios en los reinos castellano, leonés y portugués, que inmediatamente implementaron mecanismos para fijar una geografía eclesiástica durante el siglo X II y principios del XIII.

2 Más matices, sobre todo proponiendo dataciones tempranas, ofrece el análisis de BO LÓ S y PAGÉS (1982).

3 Datos del Inventario Arqueológico de la Provincia de Salamanca. 
Los datos que poseemos para Riba Côa corroboran esa visión. Por un lado, se detecta la convivencia entre formas antropomorfas y no antropomorfas en un mismo yacimiento, sin que pueda hablarse de secuencias cronológicas diferenciadas. Así sucede con algunas necrópolis que poseen un número elevado de enterramientos, donde pueden encontrarse tanto tumbas ovaladas como antropomorfas. N ave do Moiro (Malpartida, C. Almeida), Mimosa (Mata de Lobos, C. Figueira de Castelo Rodrigo) o N egrelhos (Vascoveiro, c. Pinhel) son buenos ejemplos de ello (ENDOVÉLICO; BO RGES, 1997: 107). Pero más llamativos son aquellos yacimientos en los que en un pequeño afloramiento rocoso se observan tipos distintos, dado que lo reducido del sitio hace sospechar que no hubo fases cronológicas diferenciadas, sino enterramientos cercanos en el tiempo. En el lugar de Murtórios (Bouça Cova, c. Pinhel), se conservan dos tumbas, una ovalada y otra antropomórfica, situadas sobre un mismo bolo (EN D O VELICO ). Pero quizá el ejemplo más ilustrativo provenga de Vale da Igreja (A zinhal, c. Almeida), donde subsisten cuatro sepulturas sobre el mismo afloramiento, una de las cuales está muy deteriorada; de las otras tres, una es ovalada y dos antropomorfas (PERESTRELO, 2003: 31-32; fig. 2). Parece más lógico pensar que las diferencias formales se vinculan a modas 0 quizá a las condiciones de ejecución del trabajo en la piedra, sin que puedan advertirse fases cronológicas.

Un dato relevante es la frecuente vecindad de las tumbas excavadas en roca con vestigios de época romana, generalmente cerámica de construcción (tégulas) y común. En estos casos, las sepulturas se encuentran en zonas periféricas con respecto a las áreas de dispersión de tales hallazgos. Se trata de un fenómeno que se advierte también en otras zonas, como la región de Viseu (MARQUES, 2000: 218). En Riba Côa este fenómeno afecta al menos a 30 de los yacimientos con sepulturas excavadas en roca, lo que supone un $32,6 \%$ so bre el total. Un caso es el ya referido sitio de Vale da Igreja, donde se han detectado materiales de construcción, cerámica común, escoria y restos de hierro en un área de unos 7000 metros cuadrados, a 50 metros de las tumbas. Algunos lugares son especialmente elocuentes, como sucede con Verdugal (Malhada Sorda, c. A Imeida), donde se han encontrado fragmentos de cerámica de construcción, cerámica común doméstica, un fragmento de vidrio, molinos circulares, monedas de Trajano y del siglo IV, mosaicos, columnas y capiteles, por lo que parece tratarse de un antiguo vicus. En una zona relativamente periférica con respecto al espacio donde se concentran los hallazgos, hay once sepulturas excavadas en roca (FERN AN DES, 1982; PERESTRELO, 2003: 90; O SÓ RIO , 2006: 70). Muy similar es el caso de Telhões (Leomil, c. Almeida), lugar en el que se ha podido comprobar la existencia de tégulas, ímbrices, cerámica común, pesos de telar y otros restos por una superficie de 16000 metros cuadrados (PERESTRELO : 35). A pesar de que su identificación con una villa resulta excesiva, parece evidente que existió algún tipo de núcleo en época romana; a sólo unos treinta metros de allí, junto al camino y al paso de la ribeira de Leomil, se conserva una sepultura antropomorfa exenta (Fig. 3). 0 tro ejemplo procede de Tapada das Cruzes (Ruivós, c. Sabugal), donde subsiste una tumba situada cerca de una zona de hallazgos de época romana, al norte de la actual capilla de São Paulo, fuera del núcleo actual (CORREIA, 1946: 227; O SÓ RIO , 2006: 77). Por último, en Vilares (Baraçal, c. Sabugal), se han encontrado fragmentos de cerámica de construcción y común doméstica, restos de molinos circulares y elementos arquitectónicos indefinidos, todo ello posiblemente perteneciente a una aldea de época romana, en cuyas inmediaciones se observa la presencia de algunas tumbas excavadas en roca (O SÓ RIO ,2006: 38). De todos estos datos, podría inferirse una conexión entre espacios de uso en época romana y algunos de los yacimientos con tumbas excavadas en la roca. D ado el emplazamiento marginal de las tumbas, podría ser el resultado de un proceso de transformación de los núcleos de hábitat romanos. Sin embargo, no cabe descartar que determinados elementos considerados de época romana, como las tégulas, extendiesen su periodo de uso a los siglos altomedievales, por lo que los asentamientos relacionados con las inhumaciones serían posteriores a lo que se ha supuesto (GARCíA DE FIGUERO LA, 1999: 71). De todas maneras, no está comprobado 
que los núcleos señalados y las tumbas estén realmente asociados temporalmente, y podría darse la circunstancia de que no fuesen coetáneos (TEN TE y LO UREN ÇO, 1998).

La localización fuera de los núcleos aldeanos parece estar señalando la desfuncionalización de estas necrópolis para el siglo XII en Riba Côa.A penas se conocen 10 casos (10,86\%) en los que las tumbas se encuentren dentro de los núcleos de poblaciones actuales, dándose la circunstancia de que algunas de ellas están aso ciadas a determinados sitios de altura (Sortelha, Touro, N umão, Castelo Bom). De todos modos, destacan los yacimientos de Leomil (c. A Imeida) ${ }^{4}$, Q uinta de Vilar Tomé (Reigada, C. Figueira de Castelo Rodrigo) ${ }^{5}$, Fontanares (Cinco Vilas, c. Figueira de Castelo Rodrigo) y Freixo de N umão (c.Vila Nova de Foz Côa), en donde las tumbas fueron amortizadas por la construcción del atrio parroquial, probablemente en una fecha plenomedieval (MATHIAS, 1995; CO IXÃO, 1999: 132-135; CO SME, 2002: 46, 50 y 75; PERESTRELO, 2003: 35 y 38-39). Se trata en todo esos casos de lugares documentados en las fuentes escritas ${ }^{6}$, que, por otra parte, no ofrecen testimonio alguno acerca del uso de estas tumbas, ni siquiera de su existencia. Estos datos invitan a pensar que en algunas ocasiones las aldeas actuales pueden encontrarse sobre espacios cementeriales previos a la Plena Edad Media, que no necesariamente se asocian a las parroquias 0 a centros de culto. De todos modos, se aprecia cómo la mayoría de los restos conservados se emplazan fuera de las aldeas, sin una conexión aparente con éstas, e incluso los asentamientos que podrían asociarse con ellos no pueden identificarse en las fuentes escritas.To do ello induce a plantear como hipótesis que este modelo de inhumación no llegó al siglo XII en Riba Côa y puede aceptarse grosso modo una datación de estas tumbas, mediante inferencias y datos indirectos, que iría desde el siglo VII -e incluso antes- hasta el XI. Resulta, sin embargo, imposible aún definir con claridad fases internas que a buen seguro debieron existir, lo que impide afinar más la cronología.

\section{LAS TUMBAS COMO ELEMENTO VISIBILIZADOR DEL POBLAMIENTO}

Uno de los mayores problemas a los que debe hacer frente el investigador de los siglos post-romanos y altomedievales es la escasa visibilidad de los restos materiales de la época, tanto por la posible la utilización de cerámicas de muy pobre calidad (ASTILL y DAVIES, 1997: 112-113), como por la coincidencia parcial 0 total entre muchos de los núcleos actuales y los altomedievales (PÉRIN , 2004). En nuestra zona se da además la paradoja de que determinados elementos del paisaje, como pueden ser las necrópolis, disfrutan de una mayor visibilidad que otros, como los centros de hábitat, que apenas se han estudiado, algo que también sucede en otras áreas del centro peninsular (VIEIRA, 2004: 79). Dadas estas circunstancias, las tumbas excavadas en roca constituyen la principal guía para atisbar cómo se ordenaba el espacio rural en Riba Côa en los siglos postromanos y altomedievales. Dicha situación también suscita problemas, ya que, como sucede en otras regiones, el escaso conocimiento de los asentamientos dificulta la correcta comprensión de unas necrópolis aparentemente en pleno campo (AZKARATE, 2002). Por otro lado, se ha optado en muchas ocasiones por datar otros restos cercanos a las tumbas, y teóricamente asociados, a partir de éstas, sobre todo mediante la secuencia formalista; se trata de un

4 Hemos podido comprobar la existencia de al menos dos sepulturas: una junto a la fuente del pueblo y otra en las inmediaciones de la iglesia, hacia el Este. Se trata de hallazgos que no pueden ponerse en relación ni con la iglesia ni con el hábitat.

5 En un bolo granítico, donde se asienta una construcción, y dentro de una finca, están situadas al menos tres sepulturas antropomórficas, una de ella muy deteriorada.

60 STO LAZA, 1978: doc. 199 (1265.02); GO N ZÁLEZ, 1980-86: doc. 805 (1250.10.01);PALACIO S MARTÍN ,2000: doc. 327 (1268.04.08); ALMEIDA, A. de F., 1991: doc. 630 (1251.07). 
argumento circular basado en un vestigio sobre el que hay una considerable incertidumbre cronológica. $\mathrm{No}$ son las tumbas las que nos darán la fechación de los restos materiales, pues no pueden ofrecernos esa información, sino que han de ser los yacimientos asociados los que permitan afinar una datación. Las tumbas, en cambio, ayudan a buscar el hábitat y las áreas productivas, cuyos restos son difíciles de encontrar mediante la prospección.

Un primer aspecto en el que hay que fijarse es la relación establecida entre las inhumaciones y el poblamiento antiguo, donde destaca la relación con los procesos de transformación de las villae (LEW ITT, 2003; CHAVARRÍA ARNAU, 2004). A unque el modelo vilicario no parece haber sido un patrón frecuente en la comarca, determinados yacimientos se han interpretado como establecimiento de ese tipo; en ellos se observan huellas que hablan de una alteración en el periodo tardo o post-romano. Uno de ellos es Prazo (Freixo de N umão, c.Vila N ova de Foz Côa), donde, sobre una estructura de época romana, que viene identificándose con una villa, se levantó un centro de culto datado en época tardorromana o tardoantigua por la presencia de ciertos fragmentos cerámicos, alguno de los cuales con la supuesta representación de un crismón, un dato interpretado como síntoma de una rápida cristianización del lugar, si bien es una prueba a todas luces endeble. En torno a este lugar se creó una pequeña necrópolis de tumbas excavadas en roca, que posteriormente se expandió en época altomedieval con la presencia de tumbas de lajas, al tiempo que se llevó a cabo la ampliación del recinto cultual, que probablemente perduró hasta el siglo X II O XIII (COIXÃO, 1999: 54-124; Fig. 4). Este caso podría servir como ejemplo de un modelo de transformación de antiguas villae en centros eclesiásticos, que tiene numerosos paralelos con otras zonas de la Península Ibérica y de la Europa occidental, al calor de una reorientación de los horizontes socioeconómicos de las elites, que miran al cristianismo como una fuerza social que puede otorgarles una sólida base para su estatus. Pero los argumentos sobre esa continuidad no son claros, ya que es probable que hayan existido fases de abandono anteriores a la creación del centro de culto, y que en realidad se haya procedido a reutilizar unos materiales en ruinas, lo que incluso podría relacionarse con ciertos movimientos propiciados por la Iglesia para reaprovechar el simbolismo de determinados lugares ${ }^{7}$. En muchas ocasiones, la amortización del espacio vilicario en una iglesia o un monasterio propios fue el resultado de un proceso complejo, sin que pueda hablarse de una transformación inmediata y con posibles fases intermedias de abandono (CHAVARRíA ARN AU, 2004). Este modelo representa una de las vías posibles, ya que se detecta también la implantación de estructuras en madera sobre partes residenciales, de las que quizá tengamos un ejemplo en Barrocal (Reigadinha, c. Pinhel) (PERESTRELO y FERREIRA, 2000:103-104; PERESTRELO, 2003:74-75). Sin embargo, los restos conservados no permiten afirmar con seguridad que estemos ante una villa, sino tal vez ante un vicus.

En tal sentido, es posible que algunos vici de época romana hayan pervivido tras el siglo $V$, sirviendo como elementos estructurantes del espacio rural ribacudano ${ }^{8}$. A sí podría interpretarse la asociación entre vestigios de época romana, en especial cerámicas de construcción (tégulas) y cerámicas comunes, y tumbas excavadas en la roca, situadas éstas fuera de las áreas donde se han hallado los materiales. Ese emplazamiento puede entenderse como consecuencia de un proceso de transformaciones de estos núcleos en época altomedieval, pero también podría ser simplemente el resultado de una lógica espacial bastante común: la separación entre ámbitos residenciales y funerarios. Si así fuera, una hipótesis, pendiente de

7 EFFRO S, 2001 ha demostrado cómo en la Galia merovingia, la Iglesia utilizaba los materiales de estas edificaciones ya arruinadas, que habían asumido un prestigio local, el cual se transfería de esta forma a la organización eclesiástica.

8 Algo que también se ha propuesto en las necrópolis de Plames, (Vilares, c. Trancoso), Vale de El Rei (Marialva, c. Meda) o Campas (Moimenta de Maceira Dão, c. Mangualde). Vid. PERESTRELO, 2003: 59-60, 93-94; FERREIRA, 2000: 369; MARQ UES, 2000: 84; TAVARES, 1999: 43-44. 
comprobación, sería estimar como coetáneas las tumbas y los restos de época romana, cuya densidad invita a pensar en un asentamiento de tipo vicus. Desde luego esto no significa que en todos los casos exista una sincronía, ni que no haya que pensar en variaciones a lo largo del tiempo - con abandonos incluidos-, pero resulta a todas luces llamativo observar el alto índice de estaciones arqueológicas en las que es posible encontrar a menos de 500 metros de distancia restos romanos del tipo ya señalado e inhumaciones en roca $(32,6 \%)$. Cabe, por tanto, sospechar que los materiales que sirven para datar en época romana a estos lugares dispusieran de una vida más larga de la que se ha supuesto, como ya se ha señalado anteriormente. No obstante, sólo podemos hablar de una continuidad posible, pues no contamos con un registro estratigráfico, y nunca se ha de entender de manera estática, porque se produjeron al mismo tiempo profundas transformaciones, que afectaron a la producción ${ }^{9}$. De todos modos, el hecho de que Riba Côa no fuese una comarca especialmente activa en cuanto a la producción comercial durante la época romana, explicaría la aparente continuidad de ocupación de algunos lugares, frente a lo que sucedería con las villae.

La posible pervivencia de estos asentamientos procedentes de época romana no debe hacernos olvidar que la tendencia dominante en estos siglos fue la formación de nuevos núcleos de hábitat. De hecho, la mayor parte de las estaciones con tumbas excavadas en la roca no ofrecen testimonios de una posible asociación con restos del periodo romano $(67,4 \%)$, aunque este dato conviene tomarlo con cierta precaución, ya que no todos los lugares se han prospectado por igual (Fig. 5). Sin embargo, en algunos sitios se vislumbra una vinculación entre tumbas y un hábitat surgido en la Alta Edad Media, sin conexiones con el pasado romano, como ocurre con Vigia (Castelo Bom, c.A Imeida), donde se han hallado ruinas de estructuras habitacionales junto con cuatro sepulturas excavadas en la roca (PERESTRELO, 2003: 84). Se trata probablemente de un núcleo de época altomedieval que parece unido a los restos de una fortificación, que daría nombre a este lugar. Recientemente se ha señalado la idea de que fuese una atalaya de vigilancia, que daría nombre al lugar (PERESTRELO y FERREIRA, 2001: 889), aunque podría ser también un edificio residencial de un miembro de la elite local, que habría creado aquí un pequeño núcleo de hábitat. Por desgracia, el conocimiento sobre estos núcleos post-romanos es todavía muy deficiente en la comarca, ya que no se ha prestado suficiente atención a ellos. Las tumbas excavadas en roca pueden ser un buen instrumento para conocer ese elusivo poblamiento altomedieval.

N umerosos investigadores han planteado que este hábitat sería disperso, perspectiva que es frecuente también en los estudios sobre la Península Ibérica (LÓ PEZ QUIRO GA y RODRíGUEZ LOVELLE, 1997 y 1999). Un argumento para defender esa hipótesis proviene del análisis de las tumbas excavadas en roca, la mayor parte de las cuales se han conservado aisladas 0 formando pequeños núcleos de menos de 5 enterramientos. Esta circunstancia ha llevado a considerar que se trataría de espacios segregados más por familias organizadas en granjas que por comunidades que habitaban núcleos concentrados (BARRO CA, 1987:134), siendo más bien el producto de pequeños asentamientos, probablemente dispersOS (LALIENA y O RTEGA, 2005:170-172). Este fenómeno también se aprecia en Riba Côa, donde los sitios con 5 o menos enterramientos alcanzan un total de 52 yacimientos, lo que una vez eliminados los 24 de los que no se dispone datos, arroja un $76,47 \%$ (Fig. 6). La ausencia de elocuentes restos de estructuras de hábitat reforzaría esa imagen, debido a que se vincularía mejor a un poblamiento inestable. Sin embargo, consideramos que su presencia en pleno campo no sería tal, porque un análisis más detallado pondría en evidencia que hubo asentamientos cercanos, aunque quizá construidos en materiales ligeros y con una cultura material más pobre (LÓ PEZ Q UIRO GA, 2004: 160-161). Por otra parte, se ha

9 Véanse las apreciaciones de GUTIÉRREZ LLO RET, 1996: 20. Este mismo problema se le plantea a VIEIRA, 2004: 76. 
señalado que la localización de estos lugares elude las áreas ocupadas en época romana, que habrían quedado desestructuradas, por lo que nos hallaríamos ante asentamientos creados en zonas periféricas, que gozarían ahora de una centralidad hasta entonces desconocida, en buena parte sostenido por el impulso de pequeñas células monásticas de tipo "fructuosiano" que darían lugar a los asentamientos (LÓ PEZ Q UIRO GA, 2004: 155-163). Sin embargo, como ya hemos tenido ocasión de comprobar, no está tan clara esa refracción con respecto a las áreas de supuesta ocupación romana, al menos en el caso de Riba Côa.

A lgunos datos referidos a las tumbas excavadas en roca permiten dudar de la hipótesis so bre el poblamiento disperso. Los yacimientos con mayor número de tumbas se ordenan como espacios más o menos amplios destinados a la inhumación, en cuyo interior se distribuyen núcleos aparentemente inconexos que agrupan a unas pocas tumbas. Así sucede, por ejemplo, en Tapada da Raposeira (Vermiosa, c. Figueira de Castelo Rodrigo), Mimosa (Mata de Lobos, c. Figueira de Castelo Rodrigo), N egrelhos (Vascoveiro, c. Pinhel) o Nave do Moiro (Malpartida, c. Almeida) (Fig. 7). Esta aparente ordenación caótica posiblemente responda a una iniciativa básicamente familiar, en la que cada célula de este tipo segregaría un espacio funerario, aunque todos ellos se agruparían de forma laxa en un entorno único ${ }^{10}$. Parece, por tanto, que no hubo un diseño previo de estas áreas cementeriales, a lo que debe añadirse que es muy probable que, como consecuencia de las intensas transformaciones en el paisaje agrario de los últimos mil años, únicamente seamos capaces de observar fragmentos de los que debieron ser necrópolis más amplias. Así sucedería en aquellos casos en los que la relativa cercanía de puntos donde se encuen- tran sepulturas excavadas en roca aisladas hace pensar que estaríamos ante hitos fragmentarios de esos espacios cementeriales los cuales, con el transcurso del tiempo, se han visto parcialmente amortizados, como parece suceder en Barroco do Impaz (Bouça Cova, c. Pinhel) (EN D O VELICO) 0 en Fonte da Eira y Laja $\mathrm{N}$ amorada, dos lugares situados en Paraisal do Côa, a muy escasa distancia entre sí (EN D O VELICO ) ${ }^{11}$. En algunos sitios, la concentración de enterramientos en un determinado bolo se asemeja bastante a los núcleos que configuran las grandes necrópolis, por lo que podrían ser restos de un espacio de enterramiento más extenso y ya amortizado; así sucede en Vale da Igreja y también en Senhora da Ajuda (Mangide, c. Pinhel), donde se agrupan 5 tumbas en un bolo y con dos orientaciones distintas ${ }^{12}$. Por tanto, puede plantearse como hipótesis que buena parte de las tumbas aisladas sean en realidad el vestigio de áreas más extensas que, una vez abandonadas, se han visto so metidas a un proceso de desaparición debido a la erosión, a las labores agrícolas 0 a la superposición de humus y vegetación, que las oculta en la actualidad. No obstante, este patrón, que explicaría parcialmente el fenómeno de la dispersión, no tuvo por qué funcionar en to das partes, siendo factible que un porcentaje alto de las tumbas estuvieran realmente aisladas, sin configurar amplios espacios destinados a la inhumación, lo que podría conectarse con funciones de demarcación territorial de micro-espacios de uso familiar, como podremos analizar posteriormente.

Junto a los argumentos ya señalados para rebatir la ecuación entre poblamiento disperso y tumbas excavadas en la roca, debe subrayarse la posibilidad de que un mismo núcleo haya podido segregar varios espacios de enterramiento. Un ejemplo de ello sería Colmeãl de

10 Se trata de una situación que se repite en numerosas zonas, en las que se advierte la importancia de la iniciativa familiar. AZKARATE, 2002: 134

11 El primero se compone de cuatro tumbas, una de las cuales es un sepulcro integrado en un muro de propiedad, y el segundo de dos sepulturas antropomórficas.

12 Los lugareños hablan de más núcleos como éste por la zona, pero ocultos por la vegetación o en zonas poco transitables en la actualidad. 
A Imofala, en cuyo entorno se han encontrado algunos fragmentos cerámicos de época romana y medieval, así como tres núcleos de enterramientos (Fig. 8). El primero de ellos, denominado como Colmeãl das 0 las, estaría formado por dos grupos de dos sepulturas, aunque nosotros sólo pudimos observar tres tumbas, una de ellas doble. Algo más al norte, en el lugar denominado C abeço do Milreiro y en la ladera de un pequeño altozano, se hallan dos tumbas, habiéndose hallado también restos cerámicos romanos y medievales.Y más al oeste se halla la necrópolis de Mimosa, en terrenos ya de Mata de Lobos, con 22 tumbas en una zona de laderas (CO SME, 2002: 38-40;BO RGES, 1997: 56 y 107). Puede plantearse que en torno a un determinado núcleo existieran, por tanto, varias áreas cementeriales, de tipo familiar, si bien no podemos saber si eran o no coetáneas.

Esta imagen de un hábitat altomedieval disperso e inestable choca con los análisis de base arqueológica que están poniendo de relieve la presencia de núcleos concentrados en diversas áreas europeas (HAMEROW, 2002; FRAN COVICH y HODGES, 2003; VALEN TI, 2004; PÉRIN , 2004), pero también en espacios ibéricos cercanos (VIGIL-ESC ALERA GUIRA D 0, 2000). Estas nuevas interpretaciones invitan a leer los datos arqueo lógicos con cautela, ante la ausencia aún en Riba Côa de un registro altomedieval de calidad. La detección de un poblamiento disperso a partir de la distribución de las necrópolis de tumbas excavadas en roca no parece operativa, porque el instrumento de análisis no puede ser exclusivamente el estudio de las áreas de enterramiento. Éstas no permiten afirmar ni la dispersión ni la nucleación, pues no reflejan necesariamente ninguna de las dos opciones. No obstante, el diseño espacial de los sitios con tumbas excavadas en roca podría estar indicando en Riba Côa que la estructura del hábitat fuera alveo lar y que, por consiguiente, el área de hábitat estuviera distribuida en núcleos asociados entre sí de forma laxa.

Las tumbas excavadas en roca revelan además la existencia de ocupación en determinados sitios de altura, como Castelo de Prados (Prados, c. Pinhel), Castelo Bom (c. A Imeida), Castelo dos Mouros (Cidadelhe, c. Pinhel),
Castelo Melhor (c. Vila Nova de Foz Côa), Gouveias (c. Pinhel), N umão (c. Vila N ova de Foz Côa), Pinhel, Sortelha (c. Sabugal), Touro (c. Sabugal) yVilar Maior (c. Sabugal), aunque en varios casos las sepulturas estén ya amortizadas (Fig. 9). Llama la atención el hecho de que en algunos de estos sitios de altura se detecte un patrón concentrado de las tumbas. Así sucede en Sortelha (c. Sabugal) y en Numão (c. Vila Nova de Foz Côa), vinculándose además con centros de culto. No obstante, un examen atento de los restos parece mostrar que las tumbas son anteriores al edificio eclesiástico, desconociéndose hasta el momento la existencia de un centro religioso anterior al que actualmente se conserva. En Sortelha, el ábside de la iglesia de São João se levanta sobre las tumbas, respetando a sólo dos de ellas, que poseen una orientación distinta al centro de culto. Por otro lado, la ermita de São Pedro de $N$ umão, situada extramuros en su entrada septentrional, conserva 19 tumbas antropomórficas excavadas en roca, que se agrupan en torno a pequeños núcleos junto al centro de culto (LO PES, VA LEN TE y BARREIRA, 1998). D os de estas tumbas están situadas dentro de la estructura de la ermita, en la zona que correspondería al ábside, pero con una orientación suroeste, opuesta a la que posee la ermita y, en cambio, acorde con el resto de las tumbas. Todo hace pensar que estas tumbas son anteriores a la iglesia, que se ha datado en el periodo altomedieval, utilizando como argumento la forma antropomórfica de las tumbas, cuando probablemente se trate de enterramientos previos a la instauración de esa iglesia. En cuanto a Santa Maria de N umão (BARRO CA, 2000: 217; CO IXÃ O, 1996: 204-207; PERESTRELO, 2003: 175), puede observarse cómo el ábside se levantó sobre un conjunto de tumbas previo, de las que se conservan cinco, situadas en un nivel inferior a la estructura de la ermita y con una orientación divergente de ésta (Fig. 10). D eben añadirse otras dos que han sido amortizadas como parte de la muralla de la villa, probablemente en el siglo XII, por lo que cabe suponer que esta necrópolis también se situaba extramuros. Por tanto, la concentración en necrópolis, más o menos ordenadas y ubicadas fuera del recinto supuestamente fortificado, lejos de ser el reflejo de una influencia eclesiástica, podría entenderse 
como un patrón propio de los sitios de altura. Así lo confirman otros lugares cercanos como Trancoso, Moreira de Rei o Marialva (DO RDIO, 1998: 34, 38 y 39; FERREIRA, 2000: 367-368; CO RREIA, 1989: 123). El hecho de que en otros sitios de altura de la zona de Riba Côa no aparezcan estas necrópolis podría deberse a la intensa ocupación del núcleo y a la expansión de las áreas habitadas, lo que amortizó los antiguos enterramientos hasta nuestros días, por lo que sólo se conservaron algunos fragmentos como la de Santo António en Castelo Bom ${ }^{13}$.

Las tumbas excavadas en roca son un dato que apoya una ocupación de los sitios de altura que se vislumbra en los documentos escritos, como el testamento de doña Flámula al monasterio de Guimarães ${ }^{14}$. Sin embargo, carecemos de datos de índole arqueológica que ayuden a definir mejor el tipo y la cronología de las ocupaciones. Ú nicamente contamos con el caso de Sabugal Velho, donde las excavaciones realizadas han sacado a la luz un sitio de altura ocupado en época prerromana y reocupado posteriormente, aunque no es posible precisar si antes 0 después de la repoblación leonesa de los siglos X II-X III (O Só RIO , 2000 y 2001). En cualquier caso, estos sitios de altura, cuya presencia es notoria en numerosas zonas del centro y norte peninsular (BARRIOS GARCíA y MARTÍN VISO, 2000-01), parecen haber sido los ejes de territorios más amplios, que se fosilizaron en las demarcaciones forales de algunos concejos, como sucede con Vilar Maior, A lfaiates o Castelo Bom (MARTín VISO, 2005b: 107). La ausencia de análisis sobre estos centros nos impide de momento conocer si había o no estructuras que reflejasen el dominio de algún tipo de elite asentada en ellos, pero resulta la hipótesis más probable, enlazando con fenómenos que pueden rastrearse a fines del perio do romano (MARTÍN VISO, 2005a y 2005b). De todos modos, es muy posible que la jerarquización fuese poco firme, en absoluto similar a la que se solidificó con los concejos del siglo XIII en adelante.

\section{LA ORDENACIÓN DE LOS ESPA- CIOS LOCALES}

La identificación de posibles asentamientos gracias al carácter "visible" de las tumbas excavadas en roca permite un acercamiento a las estrategias de ordenación del territorio en un nivel local. Uno de los aspectos más llamativos es la relación de estos yacimientos con áreas de ribeira, es decir cursos de agua estacionales, típicos de la región, eludiendo, en cambio, las áreas endorreicas de la penillanura. Puede tomarse como ejemplo la franja en torno a la ribeira da D evesa, que vierte su cauce, actualmente represado, en la ribeira de A guiar, entre las localidades de Vermiosa y Reigada. En la orilla derecha, se encuentra la necrópolis de Tapada da Raposeira, donde se han conservado 22 tumbas excavadas en la roca, que se extienden por una plataforma granítica, en cuyas inmediaciones se han hallado fragmentos de cerámica común y de construcción, así como se aprecia la existencia de ciertas estructuras soterradas que parecen corresponder a un hábitat altomedieval, aunque este dato resulta dudoso, pues no se ha llevado a cabo una intervención específica (CO SME, 2002: 78; ENDOVELICO). De todos modos, el hecho de que este sitio no pueda relacionarse con ningún asentamiento conocido por los textos escritos, mientras que el lugar de Vermiosa aparece ya a mediados del siglo X II configurado como aldea (PALACIO S MARTín , 2000: doc. 12; GONZÁLEZ, 1944: doc. 47), parece ser un indicio acerca de su carácter de hábitat ocupado en la Alta Edad Media y ya desfuncionalizado en el siglo X II. La necrópolis se asienta sobre unos suelos graníticos difícilmente aprovechables,

13 A unque la base de datos Endovelico registra dos sepulturas antropomórficas, sólo hemos podido comprobar una, con una orientación distinta de la de la capilla.

14 PMH. DC, 1867: doc. LXXXI (960), donde Flámula entrega nostros castellos, id est Trancoso, M oraria, Longobria, Nauman, Vacinata, Amindula, Pena de Dono, Alcobria, Seniorzelli, Caria, cum alias penellas et populaturas que sunt in ipsa Stremadura. Sin duda Nauman es $\mathrm{N}$ umão, y quizá Amindula sea Almendra, aunque algunos investigadores lo identifiquen con Meda, fuera de nuestra zona de estudio (BARRO CA, 1990-91: 94). Ese mismo autor apunta la posibilidad de que Vacinata fuese el lugar de Castelo (Muxagata, C.Vila N ova de Foz Côa), pero no se han encontrado restos que permitan sostener esa hipótesis. 
formando un espacio próximo, pero separado, del posible hábitat, y a una cierta distancia de la ribeira, aunque en sus cercanías. La red vial local permite una fácil conexión con este lugar, a través de un camino que, partiendo de la carretera que une Vermiosa con Malpartida, sale hacia el oeste.

En la margen izquierda se encuentra Q uinta deVilar Tomé, que debe identificarse con Villar Pedro Tomé, lugar citado en 1250 (GO NZÁ LEZ, 1980-86: doc. 805), lo que invita a pensar que la amortización del hábitat altomedieval no fue completa y que pudo ser el origen de la red de asentamientos que vemos en los siglos X II y X III. A quí se conservan tres sepulturas excavadas en la roca situadas en un bolo granítico cercano a una construcción que posiblemente amortiza una antigua capilla. Las prospecciones realizadas han encontrado tégulas y se ha afirmado una ocupación en época romana y visigo da (CO SME, 2002: 75), aunque se trata de una adscripción cronológica muy dudosa, lo que no elimina la existencia real de un hábitat en las cercanías de la necrópolis. El emplazamiento repite el modelo ya observado en Tapada da Raposeira, con una relativa cercanía a la ribeira de Devesa, aunque apartada de ella, utilizando un espacio de emergencias graníticas y con una adecuada conexión a través de un camino que, saliendo de la carretera que va a A Imeida, se dirige hacia el Este a dicho lugar (Fig. 11). De estos datos se pueden inferir algunos parámetros de la articulación del territorio rural, con una separación entre áreas residenciales, espacios de cultivo y zonas de uso funerario, aunque las tres están cercanas y vinculadas entre sí. Las primeras se detectarían por la presencia de cerámicas comunes y de construcción, que pueden interpretarse como el vestigio de los poblados relacionados con las necrópolis; las áreas de estos hallazgos se encuentran diferenciadas de las que poseen tumbas excavadas en la roca, pero no muy lejanas de éstas. Hay además una red viaria local, que ha llegado en ocasiones a fosilizarse, y que servía de conexión entre las distintas zonas con funciones diferenciadas ${ }^{15}$. Por último, se observa cómo las necrópolis eluden las áreas más próximas a los cursos de agua, que proporcionan zonas aluviales, y las de pastizal, que eran espacios destinados al aprovechamiento económico, condicionando de esta forma la localización del hábitat. La producción debía estar organizada desde las comunidades asentadas en estos lugares.

Esta ordenación del espacio local se combina con una acusada preferencia por las zonas de ribeira, lo que denota que las pequeñas franjas aluviales generadas por ellas, donde se encuentran los mejores pastos y las áreas de mayor potencialidad agraria, constituían los principales espacios productivos. Así sucede en la zona de la ribeira de A guiar, entre Castelo Rodrigo y Mata de Lobos (c. Figueira de Castelo Rodrigo). En esta zona se suceden, de Sur a N orte, siguiendo el curso de la ribeira, los yacimientos de $G$ aleotas y $C$ anto dos Linhos, en la orilla occidental, y Sanca en la oriental, todos ellos con dos inhumaciones cada uno (BO RGES, 1997: 107; BO RGES, 2001:23, CO SME, 2002: 68-69). Se trata de tumbas aisladas, todas ellas emplazadas en los glacis que dominan la franja aluvial -área productiva que se elude- y que llevan hacia la penillanura. D e momento, resulta imposible individualizar algún tipo de hallazgo que indique la existencia de un tipo de hábitat asociado, aunque este dato no es definitivo. En cualquier caso, las semejanzas con el caso anteriormente descrito de la ribeira de D evesa son evidentes, sobre todo en lo que se refiere al emplazamiento de las tumbas (Fig. 12). Una situación similar se puede rastrear en la ribeira deTeja, en el sector de Sebadelhe (c.Vila N ova de Foz Côa), donde se hallan los yacimientos de $Q$ uinta do Areiro y Lameiras, ambos en la margen derecha de la ribeira, situados en zonas separadas del área aluvial, sobre el glacis que lleva a la penillanura, y compuestas por tumbas aisladas y en principio en campo abierto,

15 En este sentido, debe señalarse cómo en reiteradas ocasiones se ha puesto de manifiesto la cercanía de las necrópolis a vías locales; VALERA, 1993; GARCÍA DE FIGUERO LA PAN IAGUA, 1999; GUTIERREZ DO HIJO, 2001. Esta situación resulta lógica, ya que era necesaria una buena comunicación para trasladar a los cadáveres, a lo que se suma el hecho de que no eran grandes vías regionales. Pero además tales caminos servían para conectar las áreas residenciales y las destinadas al aprovechamiento agroganadero. 
sin relación con un hábitat (CO IXÃO, 2000: 386). Por otro lado, este patrón de emplazamiento en ladera sobre un pequeño curso de agua es muy frecuente, no sólo en Riba Côa, sino también en otras zonas del centro peninsular (VIEIRA, 2004; LO BÃ O, MARQ UES y N EVES, 2006), aSí como en la vecina comarca de Ciudad Rodrigo, donde estamos realizando un trabajo similar al emprendido en Riba Côa. De todo ello, puede inferirse que el emplazamiento de las tumbas nos estaría mostrando cuáles eran las áreas preferentes de ocupación y de producción, eludiendo los espacios de la penillanura frente a las ribeiras.

\section{LAS TUMBAS Y LA ORGANI- ZACIÓN DE LAS COMUNIDADES CAMPESINAS}

El estudio de los enterramientos en época altomedieval goza de una larga tradición y ha sido objeto de numerosos análisis. En los últimos años, se ha profundizado en el carácter de escenarios donde se expresan, de manera simbólica, las relaciones sociales, so bre todo en un ámbito local. Un aspecto destacado viene determinado por la deposición de ajuares, en especial de objetos vinculados a la riqueza o el poder, en muchos casos de origen militar.Tales materiales servían para subrayar el prestigio y estatus social de determinadas familias en un momento en el que los lazos tradicionales de legitimación del predominio local se habían convertido en menos efectivos y nuevos grupos de poder competían por el dominio. Dado que el rito de inhumación exigía la presencia de una audiencia, la deposición representaba públicamente el dominio social, en un contexto de inestabilidad social. La conclusión es que el enterramiento con ajuar reflejaba una sociedad donde el poder local estaba abierto y, en consecuencia, era inestable (HALSALL, 1997: 66-67; THEUW $S$ y ALKEMADE, 2000). Pero esta situación se fue modificando a lo largo del tiempo y se observa cómo en los siglos VII y VIII se produjo una disminución en la riqueza de los ajuares, acelerándose la tendencia hacia la consolidación del enterramiento sin ajuar. En este cambio convergieron diversos factores, como el aumento de la estabilidad del poder local con la subsiguiente consolidación de los cauces de dominio y la influencia de la Iglesia, cuya proyección social permitió que buena parte de la inversión aristocrática destinada a fortalecer su estatus se dirigiera precisamente hacia ciertos centros de culto locales o hacia nuevas prácticas distributivas (LA RO CCA, 1998b). Sin embargo, las tumbas excavadas en roca no permiten llevar a cabo un análisis de este tipo, ante la ausencia generalizada de ajuares, que se convierte en absoluta al hablar de armas 0 símbolos de poder. Riba Côa participa plenamente de esa situación.

En cambio, el análisis de los yacimientos con tumbas excavadas en roca permite plantear otros aspectos de la sociedad que segregó tales inhumaciones. Uno de ellos es la débil aso ciación con centros de culto coetáneos, lo que contrasta con lo que se ha propuesto en otras zonas de la Península Ibérica (CASTILLO, 1972; LÓ PEZ Q UIRO GA, 2004:157). En Riba Côa, al igual que en muchas otras zonas del centro de la Península Ibérica ${ }^{16}$, tal nexo no es frecuente y sólo 15 yacimientos (16,3\%) parecen atestiguar esa relación. Pero esas cifras deben matizarse, ya que en varias ocasiones el centro de culto es claramente posterior y su construcción se superpone a los enterramientos previos - como sucede en Sortelha, Touro, Numão y Freixo de Numão- 0 no parecen ser sincrónicos, ya que los enterramientos tienen una orientación distinta 0 no se detectan síntomas de una conexión entre centro de culto y sepulturas (São Martinho, Leomil, Santo A ntão,VilarTomé) 17. En otros casos, la asociación es difícil de defender, debido a que la separación física entre enterramientos y centros de culto es relativamente grande, por lo que no es segura su rela-

\footnotetext{
16 Sobre una base de datos que manejamos de 629 yacimientos, sólo 80 poseen algún indicio de relación con un centro de culto $(12,71 \%)$. Sin embargo, tales datos, como sucede también en Riba Côa, están posiblemente distorsionados, y un análisis más cuidadoso rebajaría aún más esa vinculación.
}

17 Se observan casos similares en la región portuguesa entre el Duero y el Miño; BARRO CA, 1987: 134. 
ción, como ocurre en N ossa Senhora daAjuda, Santa Marinha o Santa Bárbara (EN D OVELICO; BO RGES, 2001: 108; CO SME, 2002: 70-71; CO RREIA, 1946). Los casos restantes tampoco aseguran esa conexión, que únicamente parece ser realmente operativa en el ya mencionado caso de Prazo, probablemente algún tipo de centro de culto prestigioso, quizá un monasterio. Podría plantearse que algunas de las iglesias actuales que se superponen a espacios funerarios de este tipo fueran herederas de centros de culto de menor tamaño y aún desconocidos, debido a la ausencia de intervenciones. No obstante, esta posibilidad, que sólo afectaría a cuatro casos, se sustenta en datos inexistentes $y$, por tanto, no se ajusta la evidencia de la que se dispone. El resultado es esclarecedor: la conexión entre centros de culto y tumbas excavadas en roca es casi nula en Riba Côa, lo que sucede también en prácticamente en todo el centro peninsular y también en otras áreas recientemente analizadas (LALIENA y O RTEA, 2005: 180). La elección y organización del espacio cementerial no pueden entenderse como decisiones tomadas desde los ejes del poder eclesiástico, sino que se ajustan a los impulsos de las comunidades asentadas en la comarca, sin una intervención externa ${ }^{18}$. Era una sociedad cristianizada -ya que las tumbas excavadas en roca indican una inhumación en decúbito supino-, pero no ordenada desde los círculos de la Iglesia oficial. Q uizá deba relacionarse con tradiciones como las que Martín de D ume denostaba en sus capitula, donde refería la costumbre de ciertos clérigos de trasladar los oficios y sacramentos en el campo sobre las tumbas de los muertos (MARTíN DE DUME, 1950: cap. LXVIII). D ebe añadirse que la ausencia de un diseño previo en la ordenación de las inhumaciones sería otro indicador de una organización creada al margen de una iniciativa de un poder que controla el ritual. Esta ordenación local y sin intervención de poderes externos sólo cambió con la consolidación de la red parroquial, un fenómeno que viene aparejado con la repoblación. De hecho, no se establece una asociación entre parroquias plenomedievales y necrópolis de tumbas excavadas en roca, lo que parece ser un síntoma de fuertes cambios tanto en el plano social como en la ordenación del territorio local. Como corolario, la nula intervención de los loca sacra en la organización del ritual funerario expresaba las limitaciones del papel eclesiástico en el capital simbólico de las comunidades y de sus elites, lo que conllevó la ausencia de enterramientos ad sanctos que plasmasen un estatus vinculado al centro de culto, con la salvedad de Prazo. En la primera fase de la ocupación post-romana de este lugar, se detectan una serie de sepulturas alrededor de lo que se supone que es una iglesia, que, tras su ampliación hacia el $X$, absorbió estas tumbas en su atrio (COIXÃo, 1999: 53-54).

0 tro aspecto destacable tiene que ver con el estudio de las agrupaciones de tumbas y de su localización dentro de algunos yacimientos. La organización de las necrópolis con mayor número de inhumaciones constata la existencia de núcleos de dos a cinco sepulturas, que tendrían un carácter familiar, con una ordenación aparentemente caótica por la ausencia de conexión entre unos grupos y otros. Sin embargo, pueden existir rangos internos, vinculados a enterramientos con un mayor prestigio que otros. A sí sucede cuando hay núcleos en los que se detecta una tumba situada en un lugar prominente, en torno a la cual se concentran otras. Un ejemplo procede de $\mathrm{N}$ egrelhos (Vascoveiro, c. Pinhel), donde se levanta una sepultura sobre lo más alto de un bolo y a su alrededor se detectan otras dos asociadas y situadas en un plano inferior y quizá otras dos más igualmente vinculadas (Fig. 13). A unos 100 metros, junto al camino, se alza otro bolo, en donde aparecen dos tumbas, una de las cuales, antropomórfica, se encuentra a media altura y

18 Este comportamiento puede compararse con las inhumaciones aisladas dentro de algunos yacimientos altomedievales en la Île-deFrance, que se explican por la ausencia de una red parroquial bien implantada y estructurante, por lo que la elección del lugar de enterramiento constituyó un acto privado hasta los siglos IX o X. Estas sepulturas indicarían una iniciativa no controlada por la Iglesia, pero no implican la ausencia de normas, como testimonia su situación casi sistemática al margen del hábitat, en zonas específicas para este cometido. PECQ UEUR, 2003. 
otra está asociada a ella. Sin negar el carácter familiar de tales enterramientos, quizá podría hablarse de algún tipo de estatus que se desea marcar mediante un enterramiento distinguido o diferenciado. Se trata de una hipótesis difícil de comprobar y sobre la cual convendría profundizar en nuevos estudios.

Las dificultades para advertir rasgos de estatus en las necrópolis de tumbas excavadas en roca, unidas a la ausencia de ajuares que muestren un simbolismo de poder, nos hablan de una sociedad que no mostraba sus diferencias internas a través de la inhumación, quizá porque no había una fuer te competencia interna, como sucede en otros casos, o debido a que la inversión social se centraba en otros aspectos, como las funciones militares y sobre todo la propiedad de la tierra. En este último sentido, la localización de las tumbas podría estar relacionada con mecanismos para asegurar la propiedad en una sociedad que no utilizaba el documento escrito. Como se ha podido comprobar en los casos de las ribeiras de Aguiar y Teja, muchas de las sepulturas se sitúan en los glacis que dominan las áreas aluviales más llanas, cercanas a las ribeiras. Se trata de un patrón de emplazamiento en ladera que es muy frecuente en Riba Côa y en otras comarcas vecinas. La mayoría de estas tumbas se levanta sobre pequeños afloramientos que destacan sobre el resto del espacio, lo que incrementa su visibilidad relativa. Para otras zonas del Noroeste peninsular, se ha postulado que las sepulturas situadas en pequeños roquedales que se alzan sobre el terreno estarían relacionadas con la plasmación de la jerarquización interna; sería una muestra de la voluntad de enterrado y de su familia por disponer de una sepultura destacada en el paisaje (BARRO CA, 1987; LÓ PEZ Q UIRO GA, 2004). Una hipótesis, sobre la que debería profundizarse, es que tales tumbas estuviesen actuando como marcadores de un espacio productivo, perfectamente visible desde ellas. La propiedad quedaba fijada en el espacio mediante una tumba, que representaba a los ancestros de quienes derivaría la propiedad, realizada sobre un material duro (granito o pizarra generalmente) que aseguraba su perdurabilidad a lo largo del tiempo. Estas tumbas debían reutilizarse constantemente, pudiendo enterrarse en ellas a varios individuos, como se comprueba en yacimientos de otras áreas peninsulares. También podrían servir como límites entre las distintas propiedades, refo rzados por la presencia de los muertos ${ }^{19}$, e incluso podrían estar mostrando la riqueza de un individuo -el que inicialmente fue allí enterrado- y de su familia. Mediante este recurso, una determinada familia o comunidad reflejaba y aseguraba su control sobre un espacio productivo, que, en el caso ribacudano, debía orientarse preferentemente al pasto para la ganadería, sin acudir al documento escrito. También en la zona aragonesa del valle del río Martín, Laliena y O rtega (2005: 180-182) llegan a conclusiones similares; en dicha comarca, las tumbas aisladas estarían marcando derechos sobre la tierra, emplazándose sobre las terrazas aluviales, con las que se conectan visualmente, utilizando el prestigio de los ancestros como herramienta para reclamar su propiedad. En cierto modo se puede asemejar a lo que sucede con las inscripciones rúnicas escandinavas, que se erigieron para defender los derechos de propiedad de los herederos de aquellos que se conmemora, al mismo tiempo que plasmaban públicamente la riqueza y el estatus de las gentes a quienes concernían (SAW YER, 2000).

Esta hipótesis podría explicar las numerosas tumbas en pleno campo, más allá de la existencia o no de un hábitat aún desconocido. En los casos ya referidos de las ribeiras de A guiar y Teja, la presencia de pequeños núcleos de tumbas y su localización plasmarían el control familiar sobre espacios productivos concretos,

19 En la zona centro peninsular, sólo tenemos constancia de un documento escrito, ya tardío, de 1205, en el que se mencionen unas tumbas excavadas en roca, refiriéndose al valle de Valdeiglesias, en la actual provincia de Madrid (GO N ZÁLEZ, 1960: doc. 772). El texto muestra la resistencia de formas de articulación y aprovechamiento del espacio campesinas frente a la lógica de los monjes cistercienses; en ese sentido, la referencia a las tumbas sirve curiosamente como límite de unas dehesas, lo que debía ser una reminiscencia de los usos a los que hacemos referencia. Un análisis del texto en MARTíN VISO, 2002. 
relacionados con los cursos de agua, modelo que debe haber sido el más común. Pero hay variantes, sobre todo cuando estamos ante necrópolis y no tumbas aisladas. En $\mathrm{N}$ ave do Moiro (Malpartida c. Almeida), se localizan 37 tumbas en un espacio de prados junto a la ribeira das Alvercas, situándose sobre ciertos rebordes graníticos que marcan el comienzo de una suave ladera. Las tumbas se hallan dispuestas en varios núcleos, algunos de ellos bastante compactos, y también por algunas sepulturas dispersas, pero bastante próximas entre sí, utilizando los afloramientos rocosos (Figs. 14 y 15). La presencia de tan alto número de tumbas sugiere que estaríamos ante varios grupos familiares, que podrían componer una comunidad, la cual disfrutaría de los terrenos situados hacia el Este, en la ribeira, de gran potencialidad como pastos. Una situación idéntica se da en Santo André (Pinzio, c. Pinhel), donde se han conservado 18 tumbas en una ladera suave hacia el Este, desde la que se domina la ribeira das Cabras (ENDO VELICO).Y también es probable que deba interpretarse de este modo el caso de Mimosa, con 22 tumbas situadas en una zona de ladera sobre un terreno en este caso de gran riqueza agraria, que contrasta con los pequeños núcleos de Colmeãl das 0 las y Cabeço do Milreiro.

Esta hipótesis, sobre la que conviene trabajar más, no es aplicable a todos los casos y en especial a los sitios de altura. Aquí el patrón de localización tiende a situarse fuera del recinto amurallado y en grupos de tumbas. Es probable que este modelo responda a una más rígida diferenciación del espacio cementerial, buscando quizá utilizar áreas con un especial significado cultural en los que se agrupan los enterramientos de distintas familias. El emplazamiento en las inmediaciones de la posible zona fortificada, en especial próximos a caminos que se dirigen a ella, como se observa en N umão y en Castelo Bom, podría servir de memoria colectiva de los grupos familiares allí asentados. En cambio, su relación con la fijación de derechos de propiedad no debió ser un factor relevante, aunque es necesario ampliar la encuesta a otros casos para poder ofrecer algún tipo de explicación plausible.
Todas estas interpretaciones empujan a considerar a la sociedad ribacudana entre los siglos VII a XI como una sociedad campesina (MARTíN VISO , 2005a). Éstas pueden definirse como aquéllas en las que predomina la pequeña producción agroganadera controlada por las familias libres, sin que haya grandes acumulaciones de tierras en manos de una de ellas. 0 tro rasgo es que son desiguales socialmente, existiendo una diferenciación en rangos, más o menos flexibles y bastante inestables de generación en generación, de tal forma que se combina una estratificación interna y una ausencia de estatus privilegiados más allá del reconocimiento de la comunidad. Dicho estatus se basa no tanto en una masa de propiedades - si bien la riqueza relativa es un prerrequisito-, sino sobre todo en la capacidad de un determinado individuo por acumular capital simbólico mediante el ejercicio de funciones militares o sagradas. Como consecuencia, son sociedades que no suelen estar dotadas de una articulación política centralizada, por lo que pueden asemejarse a las sociedades estratificadas descentralizadas (KRISTIAN SEN , 1998), 0 aquélla es muy débil, y se rigen por normas consuetudinarias, en muchas o casiones resueltas a través de asambleas. Uno de los problemas principales con los que se enfrentan estas sociedades se refiere a los derechos de propiedad, ya que éstos otorgan al campesino su condición de partícipe activo de la sociedad (DAVIES, 1988; W ICKHAM, 1994 y 2005: 535 y ss.). En nuestra opinión, el análisis social de las tumbas excavadas en roca permite ligar el caso ribacudano -y en general el centro de la Península Ibérica- con esta definición. Se trata de una sociedad con una jerarquización débil y negociable, en donde la Iglesia como institución no participa de la vida local, mientras que resultan más importantes los aspectos derivados de los derechos de propiedad sobre áreas determinadas, que se gestionan a través de objetos de alto valor simbólico, como las tumbas. 0 tros datos que no se refieren exclusivamente a las tumbas, como la endeble jerarquización territorial, una cultura material de menor calidad y más opaca, el escaso desarrollo de la gran propiedad 0 el peso de las funciones militares en la configuración del estatus, que pueden rastrearse en la documentación de los siglos X II y X III y 
verse de manera restrospectiva, avalarían esta interpretación (MARTíN VISO, 2005b). En cambio, la repoblación leonesa y portuguesa generó un hondo proceso de cambio, no sólo político, sino social, económico y cultural que transformó profundamente las estructuras previas.

\section{BIBLIOGRAFÍA}

ALMEIDA,A. de F. (1991): Taraucae M onumenta Historica. I. Livro das doações de Tarouca. Braga.

AN D RIO GON ZALO,J. (1994): “D os necrópolis medievales. Q uintana María y Cuya Cabras (Burgos)", Boletín de Arqueología M edieval. 8, pp. 163-188.

ASTILL, G. y DAVIES, W . (1997): A breton landscape. Londres.

AZKA RATE GARA I-O LAUN ,A . (2001):“N uevas perspectivas sobre la tardoantigüedad en los Pirineos occidentales a la luz de la investigación arqueológica",ARCE,J. y DELO GU, P. (eds.), Visigoti e longobardi. Florencia, pp. 37-55.

AZKA RATE GARAI-O LAUN,A. (2002): "De la Tardoantigüedad al Medievo cristiano. Una mirada a los estudios arqueológicos sobre el mundo funerario", VAQ UERIZO, D. (ed.), Espacios y usos funerarios en el Occidente romano. Córdoba, pp. 115-140.

BARRIOS GARCÍA, Á. y MARTÍN VISO, I. (2000-01): "Reflexiones sobre el poblamiento rural altomedieval en el norte de la Península Ibérica", Studia H istorica. Historia Medieval. 18-19, pp. 53-83.

BARRO CA, M.J. (1987): Necrópoles e sepulturas medievais de Entre-o-Douro-e-M inho (séculos V a XV). 0 porto.

BARRO CA, M. (1990-91): “Do castelo da reconquista ao castelo românico (séc. IX a XII)", Portugalia. XI-X II, pp. 89-136.

BARRO C A, M. (2000): “A spectos da evolução da arquitectura militar da Beira Interior", Beira interior. História e património. Actas das I Jornadas de Património da Beira Interior. Guarda, pp. 215-228.

BEN AVEN TE SERRAN 0, J. A.; PAZ PERALTA, J. Á. y O RTíz PALO MAR, E. (2006): "De la Antigüedad tardía hasta la conquista cristiana en el Bajo A ragón", SÉN AC, Ph. (ed.), De la Tarraconaise à la M arche Supériure d'al-Andalus (IVe-Xle siècle): les habitats ruraux.Toulouse, pp. 99-119.

BO LÓ S I MASCLAN S, J. y PAGÉS I PARETAS, M. (1982): "Les sepultures excavades a la roca", RIU, M. (ed.), Necrópolis i sepultures medievals de Catalunya. Annex 1 de Acta Mediaevalia. Barcelona, pp. 59-103.

BO RGES, J. A . (1997): Figueira de Castelo Rodrigo. Roteiro turístico do concelho. Figueira de Castelo Rodrigo.

BO RG ES, J. A. (2001): Castelo Rodrigo. Passado e presente. Figueira de Castelo Rodrigo.
CASTILLO, A. del, (1970): "Cronología de las tumbas llamadas olerdolanas", XI Congreso N acional de Arqueología. Zaragoza, pp. 835-845.

CASTILLO,A. del (1972): Excavaciones altomedievales en las provincias de Soria, Logroño y Burgos. Madrid.

CHAVARRÍA ARN AU, A. (2004): "Considerazioni sulle fine delle ville in 0 ccidente", Archeologia M edievale. XXXI, pp. 7-19.

CO IX Ã O ,A. (1996): Carta arqueológica do concelho de Vila Nova de Foz Côa.Vila Nova de Foz Côa.

CO IX Ã O, A. (1999): Rituais e cultos da morte na região de entre Douro e Côa. Almada.

CO IX ̃̃ O ,A . (2000): Carta arqueológica do concelho de Vila Nova de Foz Côa.Vila N ova de Foz Côa, za ed.

CO LMEN AREJO GARCÍA, F.(1987):Arqueología medieval de Colmenar Viejo. Madrid.

CO RREIA,J. M. (1946):Terras de Riba-Côa. M emórias sobre o concelho do Sabugal. Lisboa.

CORREIA, L. (1989): Trancoso (N otas para uma monografia).Trancoso.

CO SME, S. (2002): Entre o Côa e o Águeda. Povoamento nas épocas romana e alto-medieval. 0 porto (tese de mestrado inédita).

DAVIES, W . (1988): Small worlds. The village community in early medieval Brittany. Londres.

DO RDIO , P. (1998): "Centros de povoamento: um percurso pelas vilas medievais", Terras do Côa. Da Malcata ao Reboredo. Os valores do Côa. Guarda, pp. 15-73.

EFFRO S, B. (2001):“"Monuments and memory: repossesing ancient remains in Early Medieval Gaul", DE JO NG, M.; THEUW S, F.yVAN RHIJN , C. (eds), Topographies of power in the Early M iddle Ages. Leiden, pp. 93-118.

EN DOVELICO : Base de datos de sitios arqueológicos Endovelico del Instituto Português de A rqueología (www2. ipa.min-cultura.pt).

FA BIÁN ,J. F. et alii (1986):"Los poblados hispano-visigodos de "C añal", Pelayos (Salamanca). Consideraciones sobre el poblamiento entre los siglos V y VIII en el SE. de la provincia de Salamanca", I Congreso de Arqueología M edieval Española. Zaragoza, vol. II, pp. 187-202.

FERN AN DES, I. c. (1982): “Vestígios proto-históricos e romanos de Verdugal", Actas e memórias do 10 Colóquio de Arqueologia e História do concelho de Penamacor. Penamacor, pp. 57-64.

FERREIRA, Ma (2000): “Contributos para a carta arqueológica do concelho de Trancoso", Beira interior. História e Património. Actas das I Jornadas de Património da Beira Interior. Guarda, pp. 361-374.

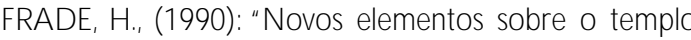
romano de Almofala", Conimbriga. XX IX , pp. 91-101.

FRAN CO VICH, R. y HO DGES, R. (2003): Villa to village. The transformation of the roman countryside in Italy, $C$. 400-1000. Londres. 
GARCíA CAMIN O, I. (2002): Arqueología y poblamiento en Bizkaia, siglos VI-XII. La configuración de la sociedad feudal. Bilbao.

GARCÍA DE FIGUERO LA PAN IAGUA, M.(1999):Arqueología romana y altomedieval de la Sierra de Gata (EI Valle de Valverde. Provincia de Cáceres). Cáceres.

GIL ZUBILLAGA, L. y SÁEN Z DE URTURI, P. (2001): San M iguele. La necrópolis tardorromana, tardoantigua y altomedieval de San Miguele (M olinilla, Álava).Vitoria

GO MES, M. v. (2002): "A necrópole visigótica do Poço dos mouros (Silves)", Revista Portuguesa de Arqueologia. 5-2, pp. 339-391.

GO N ZÁLEZ, J. (1944): Alfonso IX. Madrid.

GO N ZÁLEZ, J. (1960): El reino de Castilla en la época de Alfonso VIII. Madrid.

GO N ZÁLEZ,J.(1980-86): Reinado y diplomas de Fernando III. Córdoba.

GUTIÉRREZ DOHIJO,E. “¿Dos necrópolis entre la Antigüedad y el Medievo? El Q uintanar de Montejo deTiermes y la rupestre de Tiermes (Soria)", V Congreso de Arqueología Medieval Española.Valladolid, vol. I, pp. 115-123.

GUTIÉRREZ LLO RET, S. (1996): La Cora de Tudmir, de la Antigüedad Tardía al mundo islámico. Poblamiento y cultura material. Madrid.

HALSALL, G. (1995): Settlement and social organization. The Merovingian region of M etz. Cambridge.

HALSALL, G. (1997): Early medieval cemeteries. An introduction to burial archaeology in the post-roman West. Londres.

HAMERO W, H. (2002): Early medieval settlements. The archaeology of rural communities in North-West Europe, 400-900. 0 xford.

JIMÉN EZ PUERTAS, M. (2002): El poblamiento del territorio de Loja en la Edad Media. Granada.

KRISTIAN SEN , K. (1998): "C hiefdoms, status and systems of social evolution", KRISTIAN SEN , K. y RO W LAN DS, M. (eds.), Social transformations in archaeology. Global and local perspectives. Londres, pp. 243-267.

LA RO CCA , C. (1998a): “La trasformazione del territorio in 0 ccidente", Morfologie sociali e culturali in Europa fra Tardo Antichità e Alto Medioevo. Spoleto, vol. I, pp. 257290.

LA RO CCA, C. (1998b): "D onare distribuire, spezzare. Pratiche di conservazione della memoria e dello status in Italia tra VIII e IX secolo", BRO GIO LO, G. P. y CAN TIN O W ATAG HIN , G. (eds.), Sepulture tra IV e VIII secolo. Mantua, pp. 77-87.

LALIEN A, C. y O RTEGA,J.(2005):Arqueología y poblamiento. La cuenca del río Martín en los siglos V-VIII. Zaragoza.

LEW ITT,T. (2003): "Vanishing villas: what happened to elite rural habitation on the W est in the 5th and 6th centuries A.D.?', Journal of Roman Archaeology. 16, pp. 260-275.
LO BÃO, J. C .; MARQ UES, A. C. y NEVES, D. (2006): "Património arqueológico do concelho de Celorico da Beira: subsídios para o seu inventário e estudo", Praça Velha. 19, pp. 15-37.

LO PES, A.; VALEN TE, H. y BARREIRA, P. (1998): "Vila Velha de N umão, um projecto de investigação em curso", Terras do Côa. Da Malcata ao Reboredo. Os valores do Côa. Guarda, pp. 24-29.

LÓ PEZ Q UIRO GA, J. (2004): El final de la Antigüedad en la $\mathrm{G}$ allaecia. La transformación de las estructuras de poblamiento entre M iño y Duero (siglos V al X). La Coruña.

LÓ PEZ Q UIRO GA,J.y RO D RÍG UEZ LO VELLE,M. (1992): "Propuesta de cronología e interpretación histórica de los enterramientos en piedra en Galicia durante la A Ita Edad Media (ss.V-XI)", Boletín de Arqueología Medieval. 6, pp. 139-155.

LÓ PEZ QUIROGA, J. y RODRÍGUEZ LO VELLE, M. (1997): "Un modelo de análisis del poblamiento rural en el valle del Duero (siglos VIII-X) a partir de un espacio macro-regional: las tierras galaico-portuguesas", Anuario de Estudios Medievales. 27/2, pp. 687-749.

LÓ PEZ Q UIRO GA,J.y RO D RÍG UEZ LO VELLE,M. (1999): “L'habitat dispersé de la Galice et du Nord du Portugal entre le $V^{e}$ et le $X^{e}$ siècle. Essai d'intepretation à partir de l'analyse macro et microrégionale", CURSEN TE, B. (ed.), L'habitat dispersé dans l'Europe médiévale et moderne. Toulouse, pp. 97-119.

LOYO LA PEREA, E. (1977): "N uevas aportaciones al estudio de la arqueología altomedieval en las provincias de Logroño y Burgos". XIV Congreso Nacional de Arqueología. Zaragoza, pp. 1227-1230.

MARQ UES, J. A . (1996): "Contributo para o estudo do povoamento da região de Viseu na Alta Idade Média", Máthesis. 5, pp. 205-211

MARQ UES, J. A . (2000): Sepulturas escavadas na rocha na região de Viseu. Viseu, 2000.

MARTÍN DE DUME (1950): Opera omnia. Londres (BARLOW, C.W., ed).

MARTíN VISO,I.(2002):“La comunidad y el monasterio:el señorío de Santa María en el valle de Valdeiglesias (siglos XII-XIV)", Historia Agraria. 28, pp. 139-154.

MARTíN VISO ,I. (2005a):"En la periferia del sistema: Riba Côa entre la A ntigüedad tardía y la A Ita Edad Media (siglos VI-XI)", JACIN TO, R. y BEN TO ,V. (coords.), Territórios e Culturas Ibéricas. Guarda, pp. 186-208.

MARTÍN VISO, I. (2005b): "Una frontera casi invisible: los territorios al norte del Sistema Central en la Alta Edad Media", Studia Histórica. Historia Medieval. 23, pp. 89-114.

MARTíN VISO, I. (en prensa): “Las tumbas excavadas en roca y la organización socio-espacial de la comarca de Riba Côa en la Alta Edad Media", III ConferênciasTerritórios e Culturas Ibéricas. Guarda. 
MATHIAS, M. (1995): “Elementos para o estudo do povoamento medieval do concelho de Figueira de Castelo Rodrigo, distrito de Guarda", Trabalhos de Antropologia e Etnologia. XXXV-3, pp. 495-501.

O SÓ RIO , M. (2000):“O Sabugal Velho. Primeiras achegas para o estudio de uma estaçâo arqueológica", Beira interior. H istória e património.Actas das I Jornadas de Património da Beira Interior. Guarda, pp. 209-214.

O SÓ RIO , M. (2001): “Metalurgia no povoado fortificado alto-medieval do Sabugal Velho (Sabugal, Guarda)", M il anos de fortificações na Península Ibérico e no Magreb (500-1500). Lisboa, pp. 791-794.

O SÓ RIO , M. (2006): O povoamento romano do alto Côa, Guarda.

O STO LAZA , Ma I. (1978): Colección diplomática de Santa María de Roncesvalles (1127-1300). Pamplona.

PADILLA LA PUEN TE, J. I. (2002): Yacimiento arqueológico de Cuyacabras. Despoblado, iglesia y necrópolis. Eremitorio de Cueva Andrés. Quintanar de la Sierra (Burgos). Barcelona.

PALACIO S MARTíN , B., dir. (2000): Colección diplomática medieval de la Orden de Alcántara (1157?-1494). De los orígenes a 1454. Madrid

PECQ UEUR, L. (2003) : “D es morts chez les vivants. Les inhumations dans les habitats ruraux du Haut Moyen Âge en île-de-France", Archéologie M édiévale. XXX XII, pp. 1-31.

PERESTRELO , M. (2003): A romanização na bacia do rio Côa. Lisboa.

PERESTRELO , M. y FERREIRA, Ma (2000): “Povoamento romano na bacia da ribeira de Massueime (Guarda). Alguns subsídios", Beira interior. H istória e património. Actas das I Jornadas de Património da Beira Interior. Guarda, pp. 97-120.

PERESTRELO, M. y FERREIRA, Ma (2001): “Fortificações e caminhos medievais no Médio Côa", Mil anos de fortificações na Península Ibérico e no Magreb (500-1500). Lisboa, pp. 885-893.

PÉRIN, P. (2004): "The origin of the village in early medieval Gaul", CHRISTIE, N . (ed.), Landscapes of change. Rural evolutions in late Antiquity and the early Middle Ages. Aldershot, pp. 255-278.

PMH.DC (1867): Portugaliae M onumenta Historica. Diplomata et Chartae. Lisboa.

RIBEIRO , O . (1998): Portugal. 0 M editerrâneo e o Atlântico. Lisboa.

SÁEN Z DE URTURI, F. (1990):“Memoria de los sondeos estratigráficos realizados en las inmediaciones de las " $\mathrm{Cue}$ vas de los Moros" (Corro, Á lava)", Estudios de Arqueología Alavesa. 17, pp. 179-219.
SALVATIERRA, V. y CASTILLO, J. C . (2000): Los asentamientos emirales de Peñaflor y M iguelico. El poblamiento hispano-musulmán de Andalucía oriental. La Campiña de Jaén. Jaén.

SAW YER, B. (2000) The Viking-age rune-stones. Custom and commemoration in early medieval Scandinavia. 0 xford.

SERRANO PEÑA, J. L. y CASTILLO ARMENTEROS, J. C. (2000): "Las necrópolis medievales de Marroquíes Bajos (Jaén). A vance de las investigaciones arqueológicas", Arqueología y Territorio Medieval. 7, pp. 93-120.

TAVARES, A. L. (1999): Sepulturas escavadas na rocha no concelho de Mangualde. Mangualde.

TEN TE, C . y LO UREN ÇO,S. (1998):"Sepulturas medievais escavadas na rocha dos concelhos de Carregal do Sal e Gouveia: estudo comparativo", Revista Portuguesa de Arqueología. 1-2, pp. 191-218.

THEUW S, F. y ALKEMADE, M. (2000): "A kind of mirror for men: sword depositions in late antique Northern Gaul", THEUW S, F. y N ELSO N , J. L. (eds.), Rituals of power. From late Antiquity to the early Middle Ages. Leiden, pp. 401-476.

VALEN TI, M. (2004): L'insediamento altomedievale nelle campagne toscane. Paesaggi, popolamento e villaggi tra VI e IX secolo. Florencia.

VALERA ,A .C . (1993): Património arqueológico do concelho de Fornos de Algodres. Lisboa.

VIEIRA, M. A. (2004): Alto Paiva. Povoamento nas épocas romana e alto-medieval. Lisboa.

VIGIL-ESCALERA GUIRAD 0,A. (2000): “C abañas de época visigoda: evidencias arqueológicas del sur de Madrid. Tipología, elementos de datación y discusión", Archivo Español de Arqueología. 73, pp. 223-252.

VIG IL-ESC ALERA GUIRAD O , A . (2006): “El modelo de poblamiento rural en la meseta y algunas cuestiones de visibilidad arqueológica". LÓ PEZ Q UIRO GA, J.; MARTíN EZ TEJERA, A. M.Y MARÍN DE PABLOS, J. (eds.) Gallia e Hispania en el contexto de la presencia "germánica" (s. V-VIII). 0 xford, pp 89-108.

W ICKHAM, C. (1994): "Problems of comparing rural societies in early medieval Europe", W IC KH AM , C ., Land and power. Studies in Italian and European social history, 400-1200. 0 xford, pp. 201-225.

W IC KHAM, C . (2005): Framing the early Middle ages. Europe and the Mediterranean, 400-800. 0 xford.

YÁÑ EZ, G . I. et alii (1994): “Excavaciones en el conjunto funerario de época hispano-visigoda de La Cabeza (La Cabrera, Madrid)", Pyrenae. 25, pp. 259-287. 
APÉNDICE 1. YACIMIENTOS CON TUMBAS EXCAVADAS EN ROCA EN RIBA CÔA

\begin{tabular}{|c|c|c|}
\hline Yacimiento & Localidad & Área \\
\hline Aldeia de Santo António & Urgueira & Sabugal \\
\hline Aldeia Velha & Aldeia Velha & Sabugal \\
\hline Amoreira & Amoreira & Almeida \\
\hline Arroios & Bísmula & Sabugal \\
\hline Badamalos & Badamalos & Sabugal \\
\hline Barrocal/Santo Antão & Mata de Lobos & Figueira de Castelo Rodrigo \\
\hline Barroco da Larica & Lamegal & Pinhel \\
\hline Barroco do Impaz 1, 2 y 3 & Bouça Cova & Pinhel \\
\hline Cabeço do Milreiro & Almofala & Figueira de Castelo Rodrigo \\
\hline Caminho da Senhora da Menina & Lamegal & Pinhel \\
\hline Canto dos Linhos & Castelo Rodrigo & Figueira de Castelo Rodrigo \\
\hline Carilho & Castelo Bom & Almeida \\
\hline Casa do Muro & Chãs & Vila N ova de Foz Côa \\
\hline Castelo de Prados & Prados & Pinhel \\
\hline Cesarão & Vilar Maior & Sabugal \\
\hline Cidadelhe & Cidadelhe & Pinhel \\
\hline Colmeãl das O las & Almofala & Figueira de Castelo Rodrigo \\
\hline Cova da Moira o Moura & Algodres & Figueira de Castelo Rodrigo \\
\hline Cova da Moura/São Martinho & Colmeãl & Figueira de Castelo Rodrigo \\
\hline Crelgo & Vila N ova de Foz Côa & Vila N ova de Foz Côa \\
\hline Espedrada & Freixedas & Pinhel \\
\hline Folhinha & Bouça Cova & Pinhel \\
\hline Fonte da Eira & Paraisal do Côa & A Imeida \\
\hline Fonte Esperão & Aldeia Velha & Sabugal \\
\hline Francelha & Rapoula do Côa & Sabugal \\
\hline Freineda Gare & Freineda & Almeida \\
\hline Galeotas & Mata de Lobos & Figueira de Castelo Rodrigo \\
\hline Gorgolixa & Bouça Cova & Pinhel \\
\hline Gouveias & Gouveias & Pinhel \\
\hline Horta Cabeira & Ruivós & Sabugal \\
\hline Ladeiras & Sebadelhe & Vila N ova de Foz Côa \\
\hline Lagariças 1 y 2 & Bouça Cova & Pinhel \\
\hline Laja N amorada/C ortiças & Paraisal do Côa & A Imeida \\
\hline Lameiro do Pombal & Ruivós & Sabugal \\
\hline Lapa & Freineda & Almeida \\
\hline Leomil & Leomil & Almeida \\
\hline Luzelos & Bizarril & Figueira de Castelo Rodrigo \\
\hline Mimosa & Mata de Lobos & Figueira de Castelo Rodrigo \\
\hline Moradios/Verdugal & Malhada Sorda & Almeida \\
\hline Murtórios/Lapa do Coveiro 2 & Bouça Cova & Pinhel \\
\hline N ave do Moiro-Enchida da Sarça & Malpartida & Almeida \\
\hline N egrelhos & Vascoveiro & Pinhel \\
\hline N ossa Senhora da Assunção & Touro & Sabugal \\
\hline Paredes Velhas & Vale Verde & Almeida \\
\hline Pesqueira & Vale das Éguas & Sabugal \\
\hline
\end{tabular}




\begin{tabular}{|c|c|c|}
\hline Pomares & Pomares & Pinhel \\
\hline Ponte Pedrinha-Sapateira & Pereiro-Vale Verde & Pinhel \\
\hline Porto Mancal & Miuzela & Almeida \\
\hline Pradinhos & Alfaiates & Sabugal \\
\hline Prado da Estrada & Vale Verde & Almeida \\
\hline Prazo & Freixo de N umão & Vila Nova de Foz Côa \\
\hline Q uadrelas & Algodres & Figueira de Castelo Rodrigo \\
\hline Q uinta da Barca & Chãs & Vila N ova de Foz Côa \\
\hline Q uinta da Lapa & Ade & Almeida \\
\hline Q uinta da Sainça & Freixedas & Pinhel \\
\hline Q uinta da Urgueira & Manigoto & Pinhel \\
\hline Q uinta das Barrentas & Casteleiro & Sabugal \\
\hline Q uinta de Vilar Tomé & Reigada & Figueira de Castelo Rodrigo \\
\hline Q uinta do A reiro & Sebadelhe & Vila N ova de Foz Côa \\
\hline Q uinta dos Ferreiros & Prados & Pinhel \\
\hline Ribeira da C arrasqueira & Algodres & Figueira de Castelo Rodrigo \\
\hline Ribeiro de Forno/C ampanas & Castelo Bom & Almeida \\
\hline Sanca & Mata de Lobos & Figueira de Castelo Rodrigo \\
\hline Santa Bárbara & Bísmula & Sabugal \\
\hline Santa Catarina & $\mathrm{N}$ ave & Sabugal \\
\hline Santa Maria & N umão & Vila Nova de Foz Côa \\
\hline Santa Marinha-Santo Marinho & Penha de Águia & Figueira de Castelo Rodrigo \\
\hline Santa Trindade & Pinhel & Pinhel \\
\hline Santo André & Pinzio & Pinhel \\
\hline São João & Sortelha & Sabugal \\
\hline São Lourenço & Vale das Eguas & Sabugal \\
\hline São Marcos da Palumbeira-Fontanares & Cinco Vilas & Figueira de Castelo Rodrigo \\
\hline São Martinho & Castelo Bom & Almeida \\
\hline São Pedro & Freixo de N umão & Vila N ova de Foz Côa \\
\hline São Pedro & N umão & Vila N ova de Foz Côa \\
\hline Sarzedas & Forcalhos & Sabugal \\
\hline Senhora da Ajuda & Mangide & Pinhel \\
\hline Sepultura do Lamegal-Lamegal Velho & Lamegal & Pinhel \\
\hline Sepulturas do Carrascal & Atalaia & Pinhel \\
\hline Tapada da Eira & Freixo de N umâo & Vila N ova de Foz Côa \\
\hline Tapada da Lage & Ruivós & Sabugal \\
\hline Tapada da Raposeira & Vermiosa & Figueira de Castelo Rodrigo \\
\hline Tapada das Cruzes & Ruivós & Sabugal \\
\hline Telhões & Leomil & Almeida \\
\hline Terra do Senhor & Ruivós & Sabugal \\
\hline Vale da Igreja & Azinhal & Almeida \\
\hline Vale da Vila & Rebolosa & Sabugal \\
\hline Vale de Areia & A talaia & Pinhel \\
\hline Vale de Moinhos & Mata de Lobos & Figueira de Castelo Rodrigo \\
\hline Vale de O Imos & Vermiosa & Figueira de Castelo Rodrigo \\
\hline Vigia & Castelo Bom & Almeida \\
\hline Vilares & Baraçal & Sabugal \\
\hline
\end{tabular}




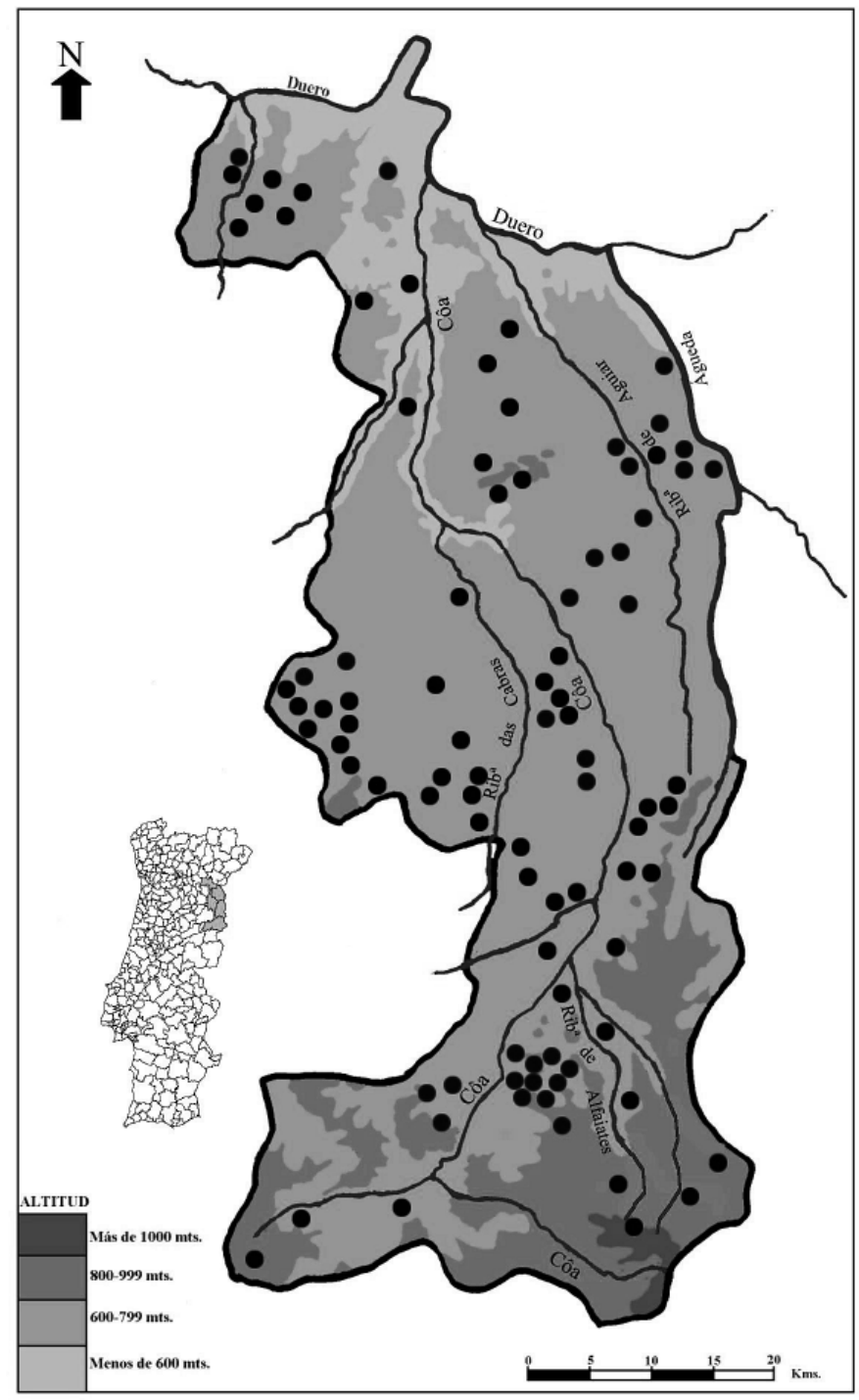

Fig. 1. Localización de Riba Côa y de los yacimientos con tumbas excavadas en roca en Riba Côa.

Fig. 2. Tumbas 1 y 3 de Vale da Igreja (Azinhal)
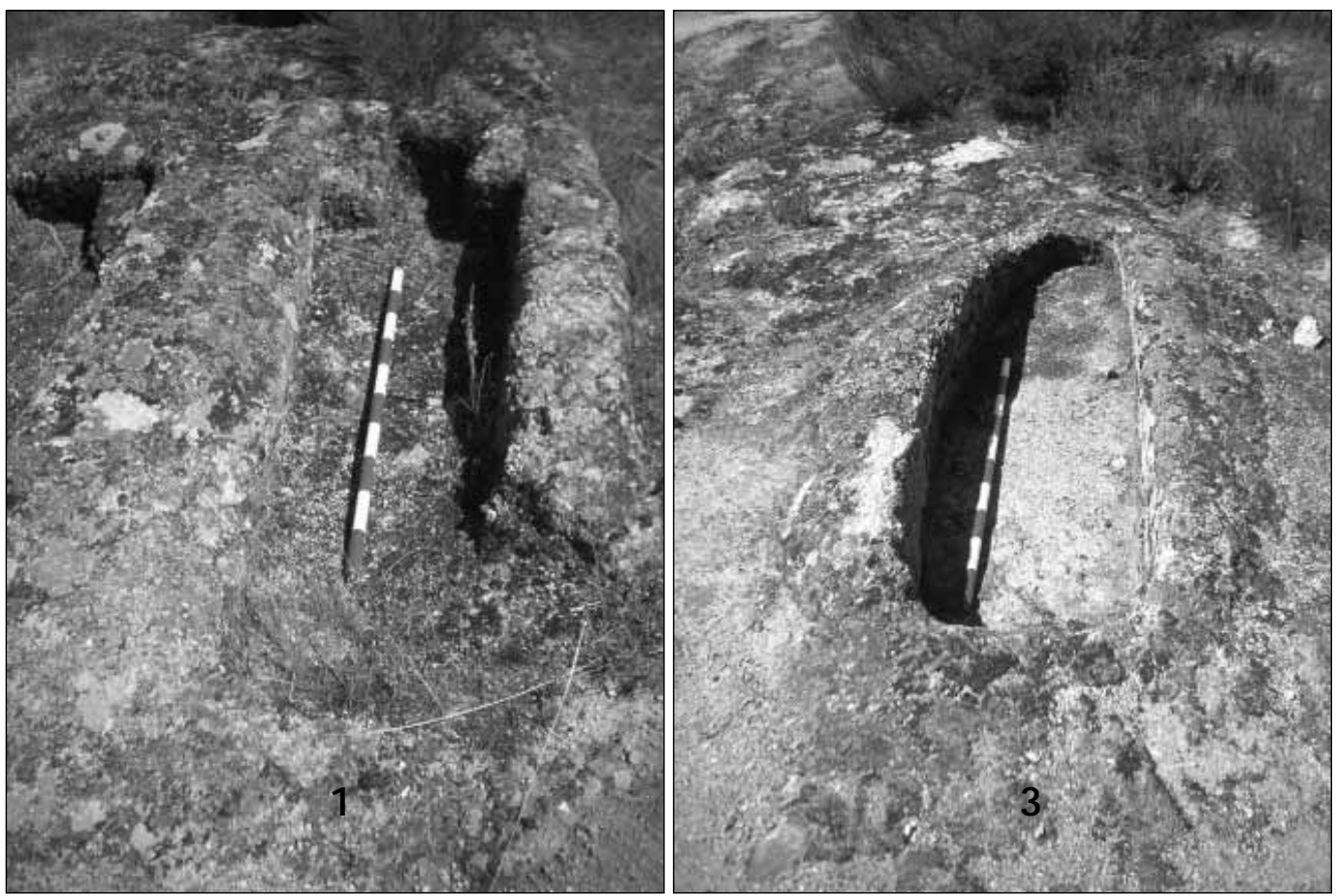


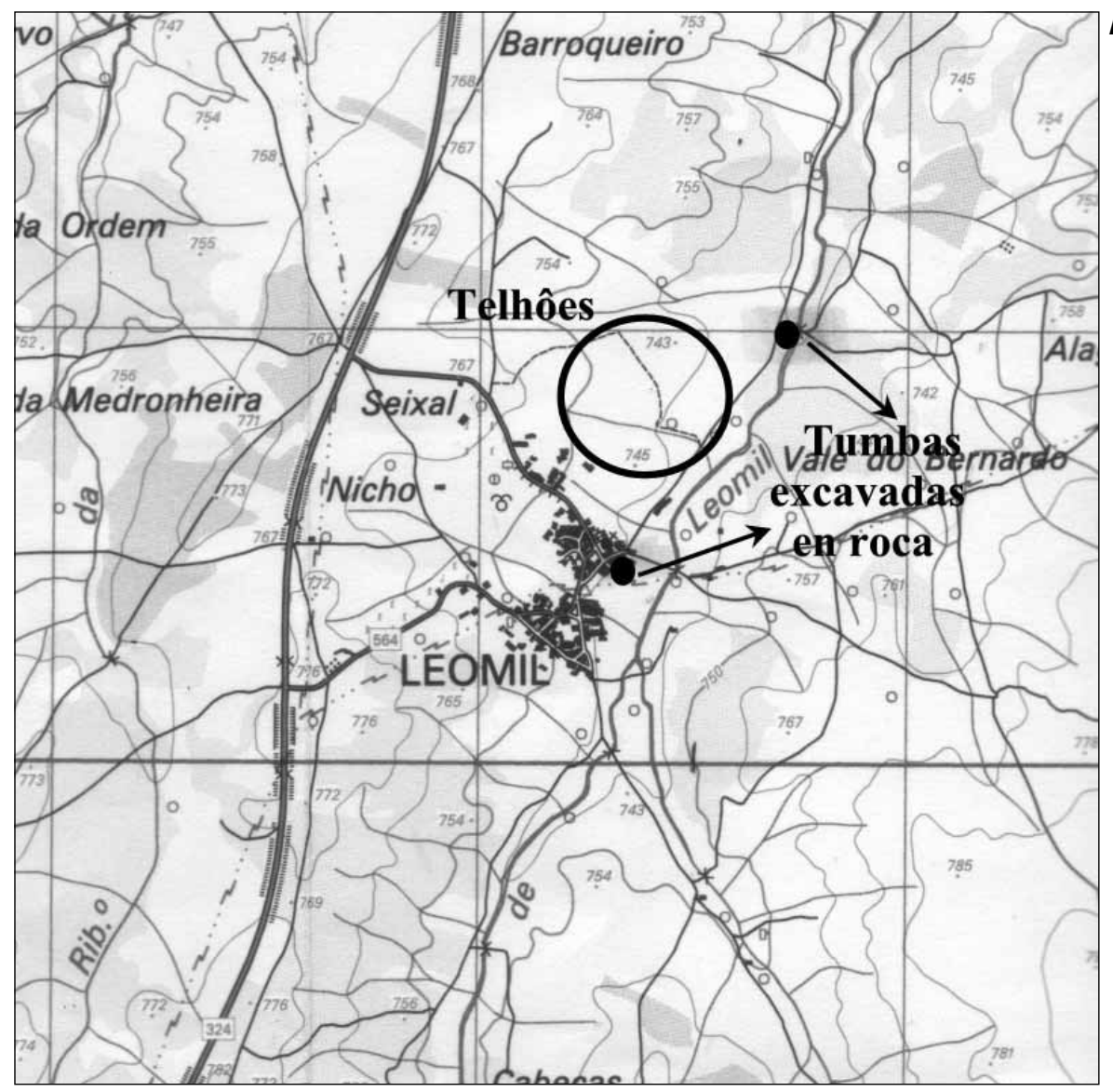

Fig. 3. El sitio de

Telhões (Leomil)

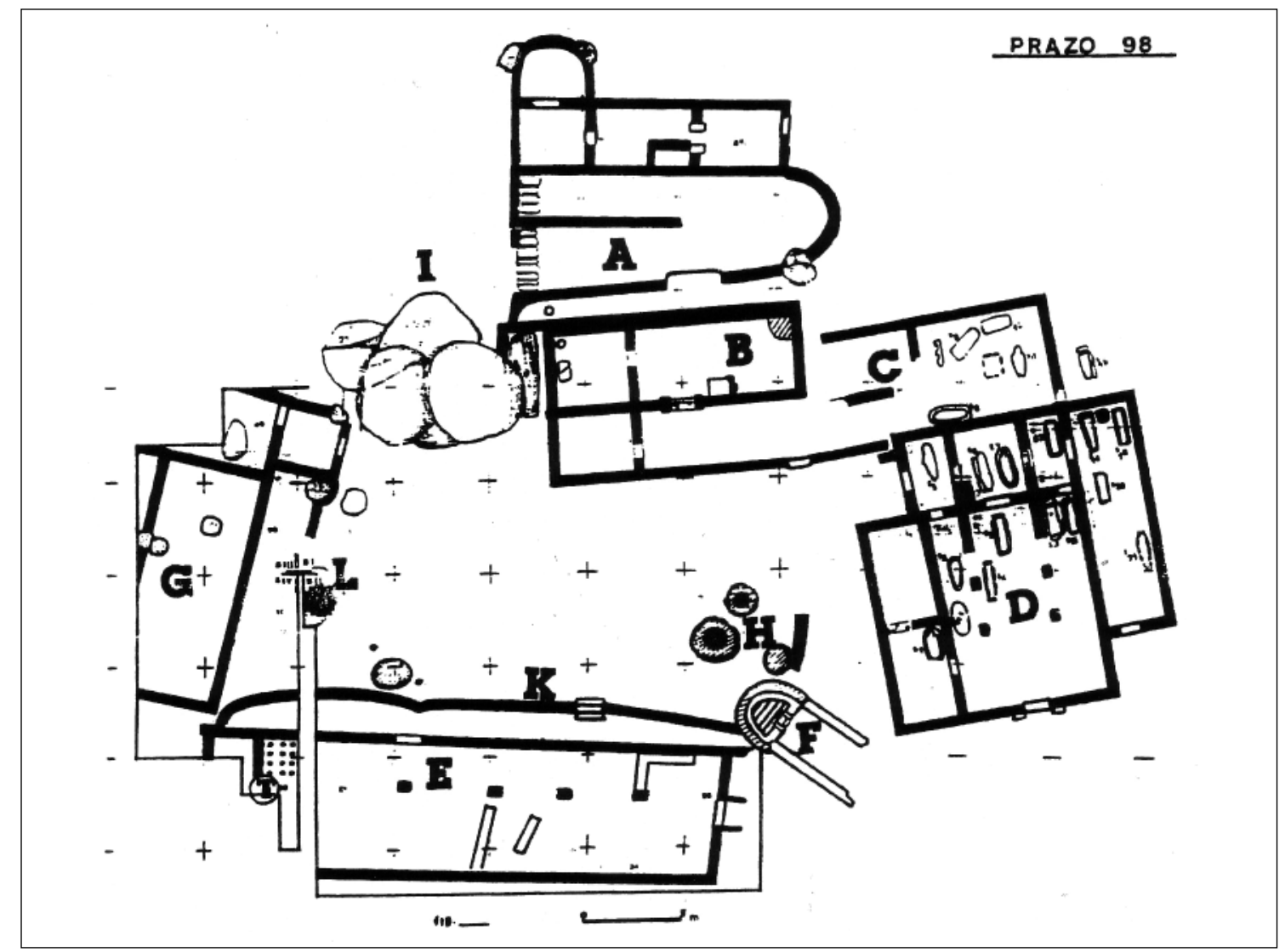

Fig. 4. El yacimiento de Prazo (Freixo de Numão). Sacado de: COIXÃO, 1999: 60 


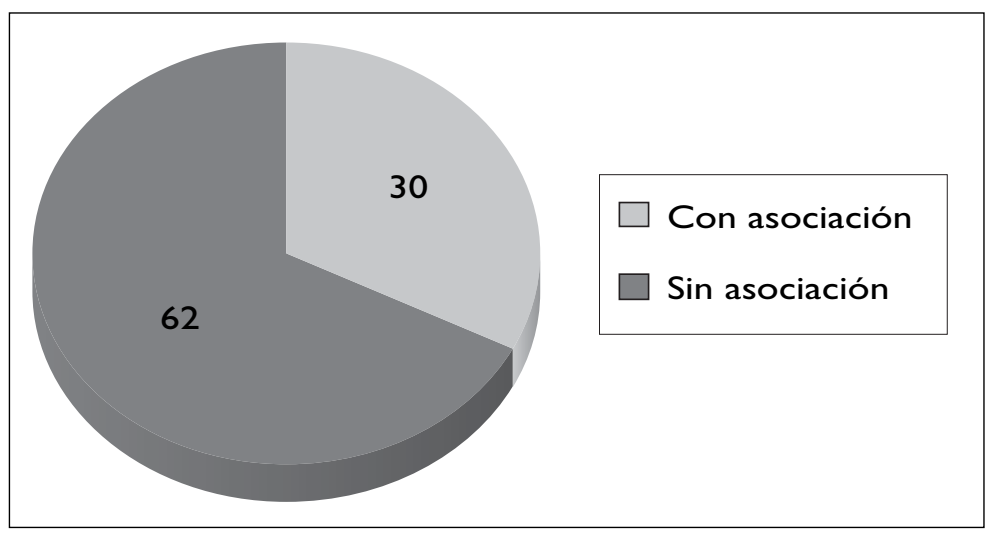

Fig. 5. Yacimientos con tumbas excavadas en roca asociados a restos romanos

Fig. 6. Número de sepulturas por yacimiento en Riba Côa
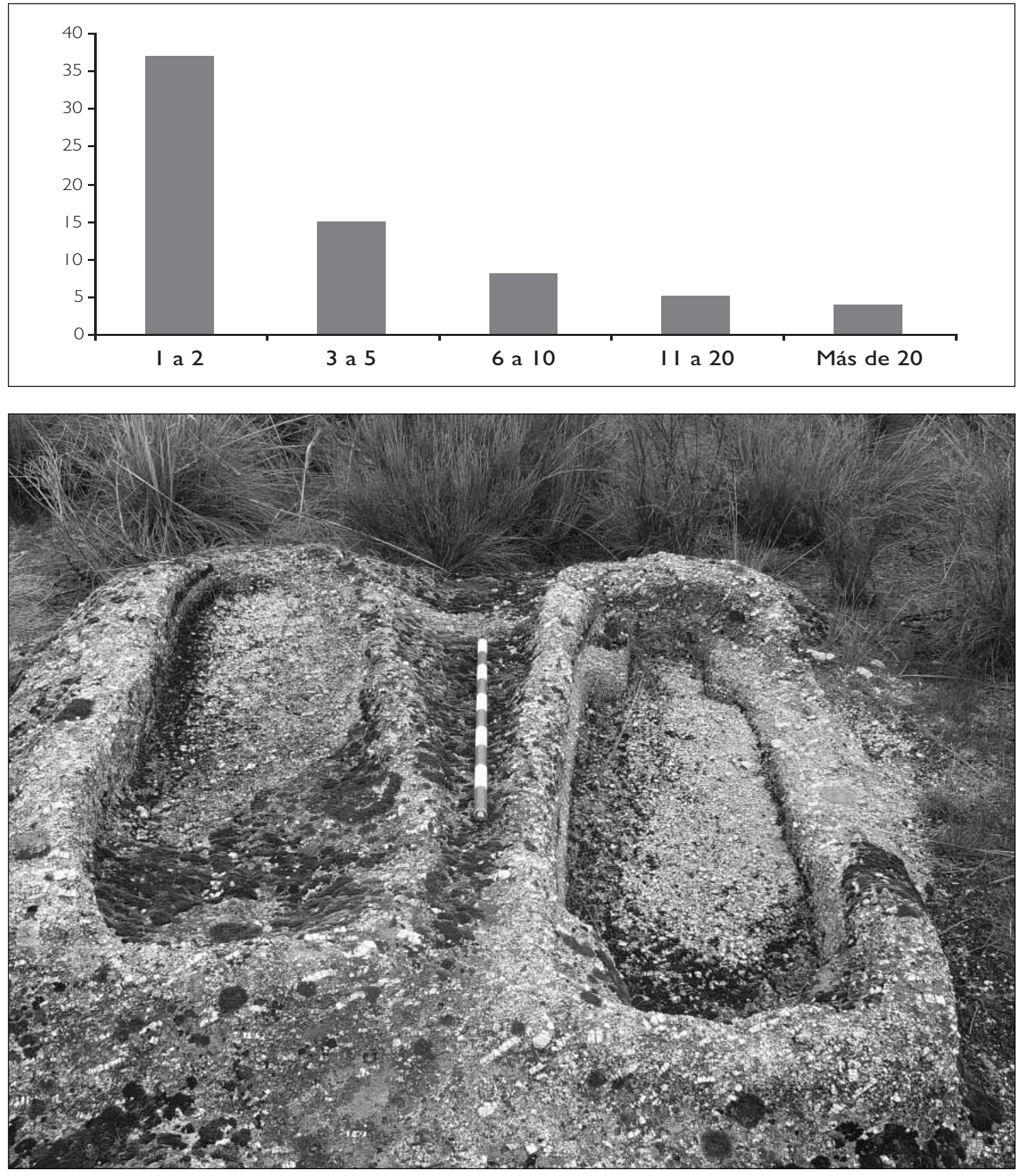

Fig. 7. Tapada da Raposeira (Vermiosa): núcleo de dos tumbas (de bañera y antropomorfa) 


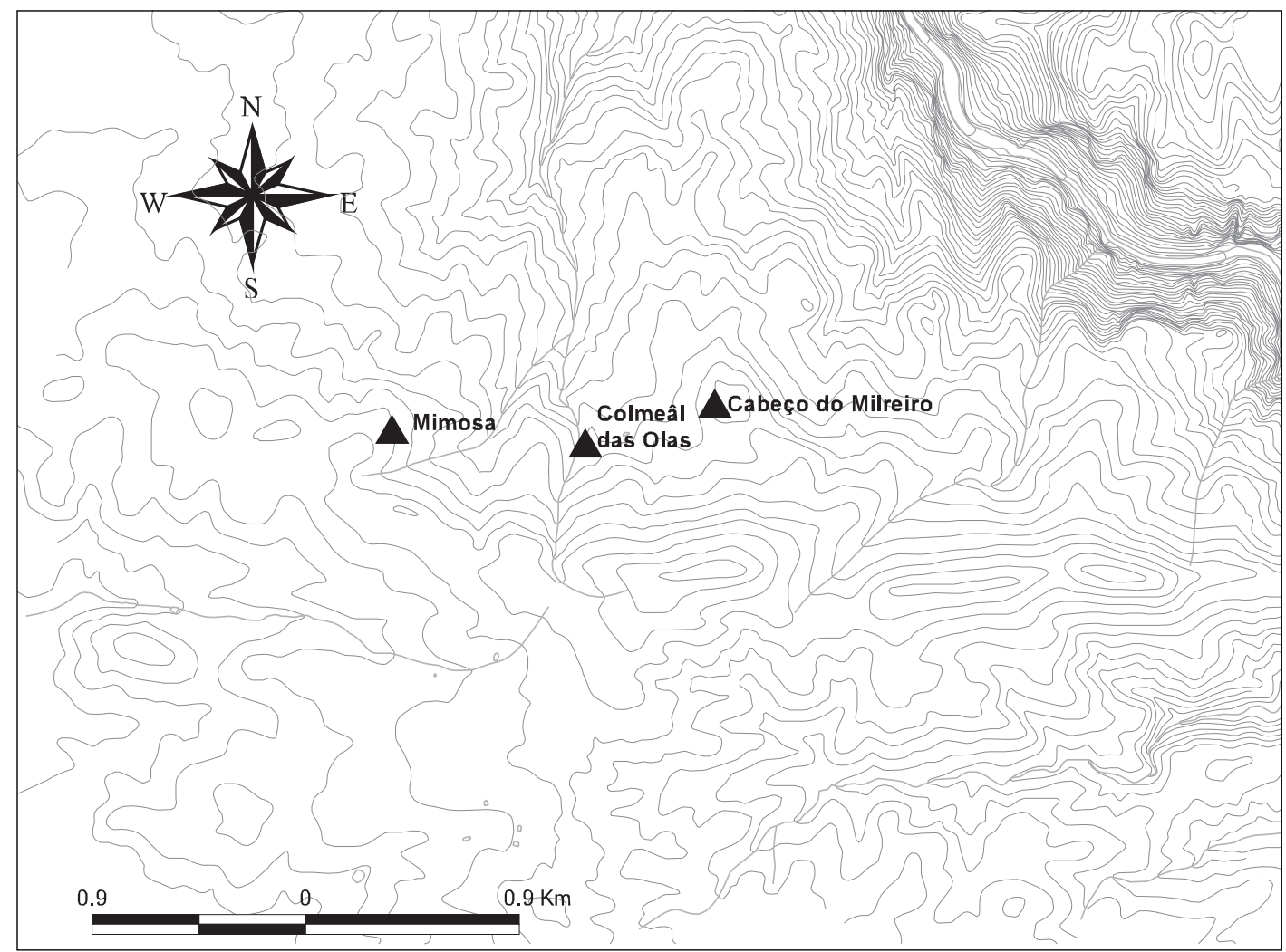

Fig. 8. Yacimientos con tumbas excavadas en roca en torno a Colmeãl (Almofala)

Fig. 9. Sitios de altura con yacimientos de tumbas excavadas en roca

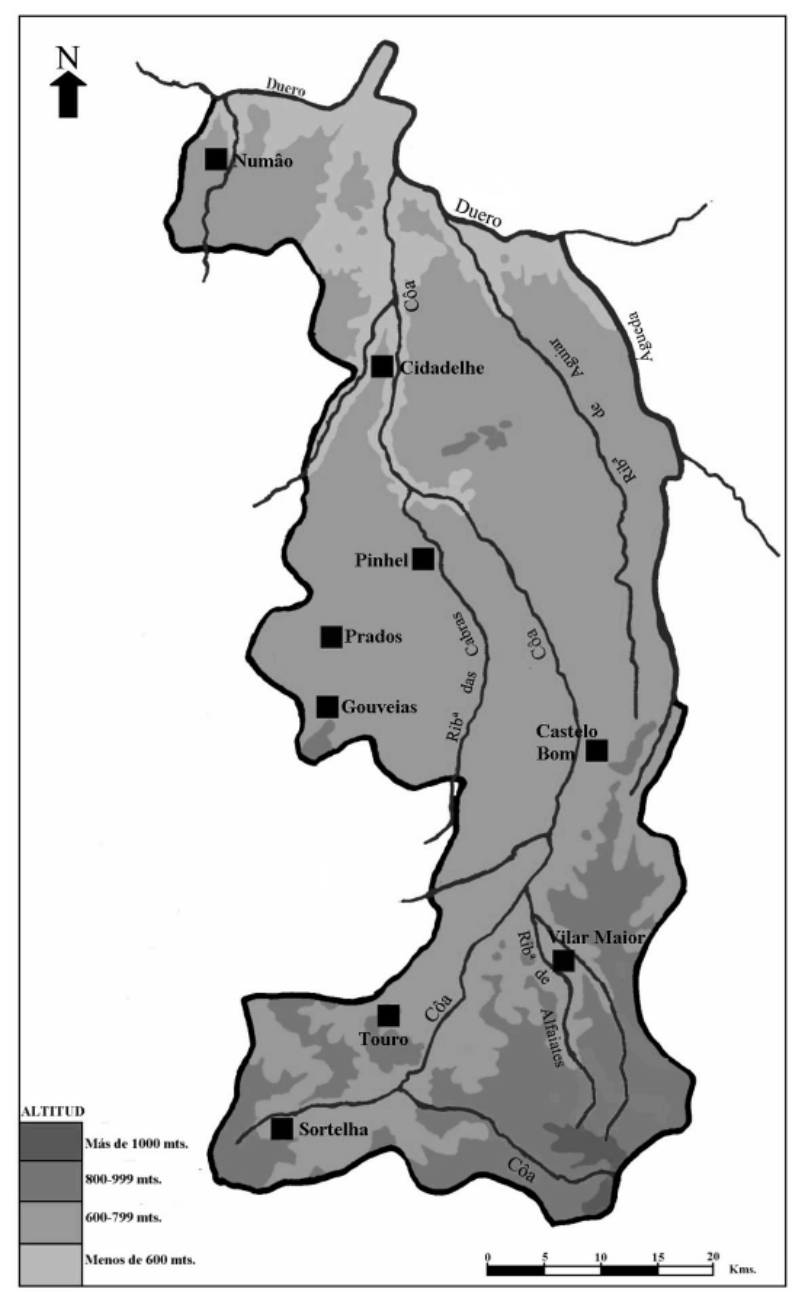




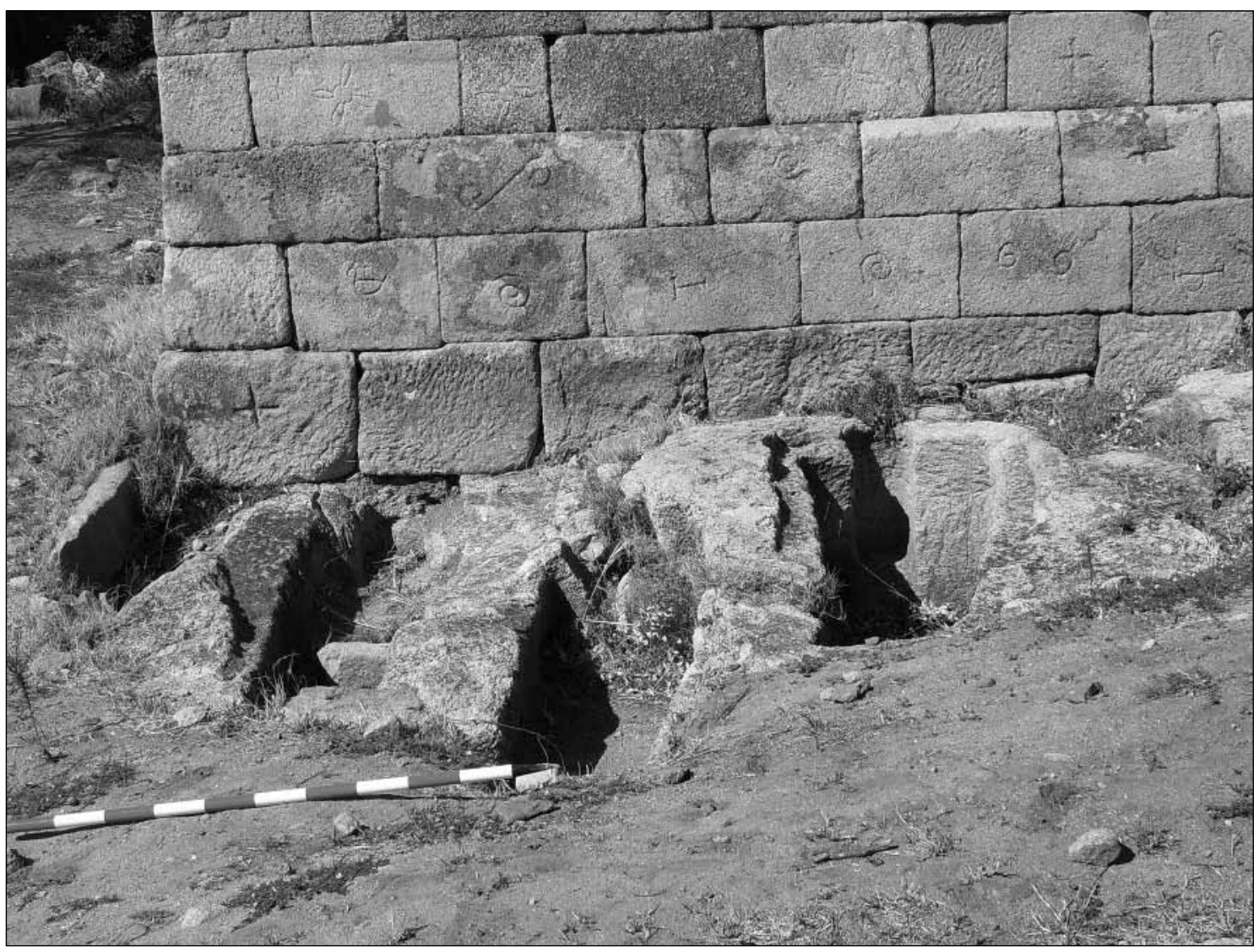

Fig. 10. Santa Maria de Numão: tumbas junto al ábside

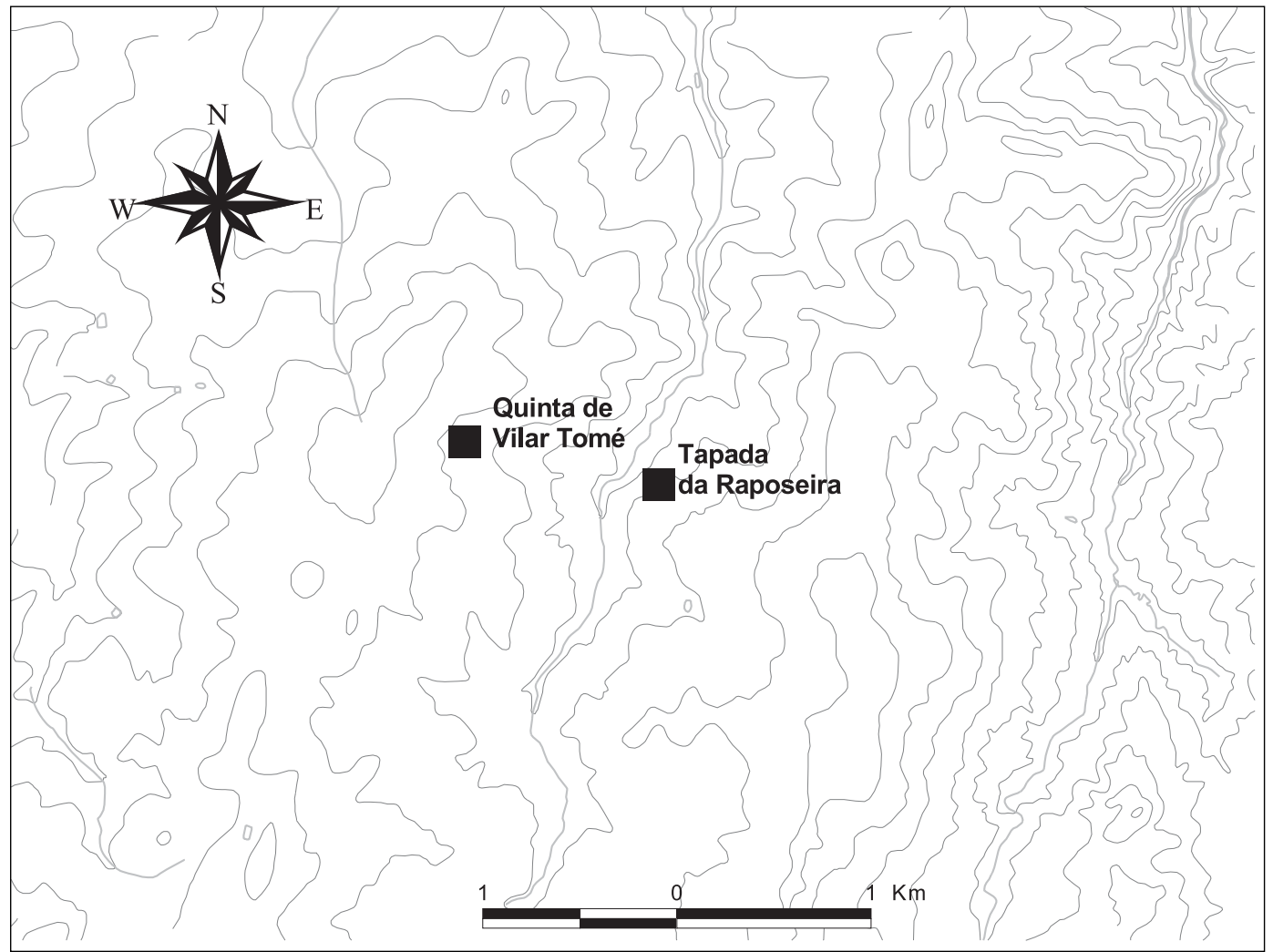

Fig. 11. Necrópolis en el área de la ribeira de Devesa 


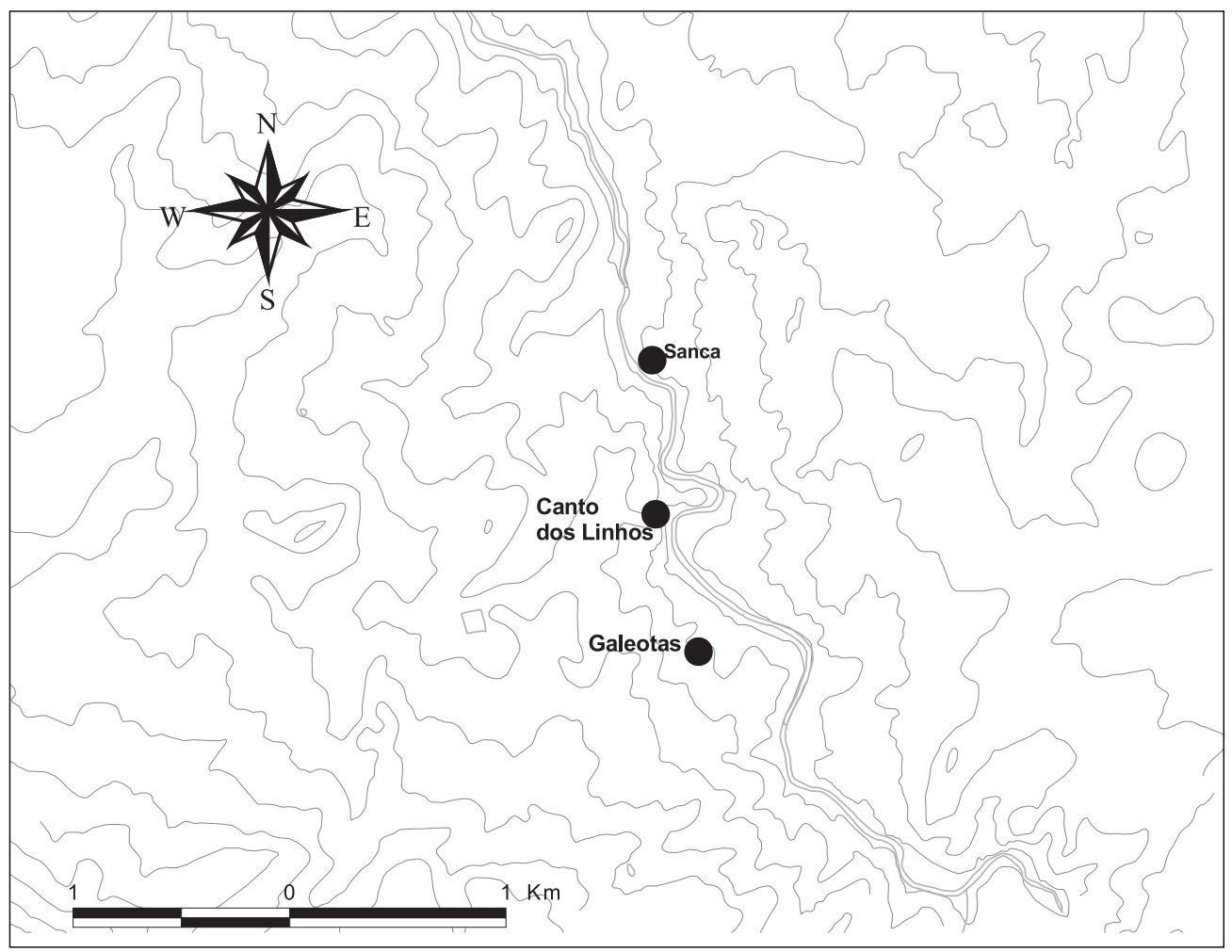

Fig. 12. Tumbas en la ribeira de Aguiar

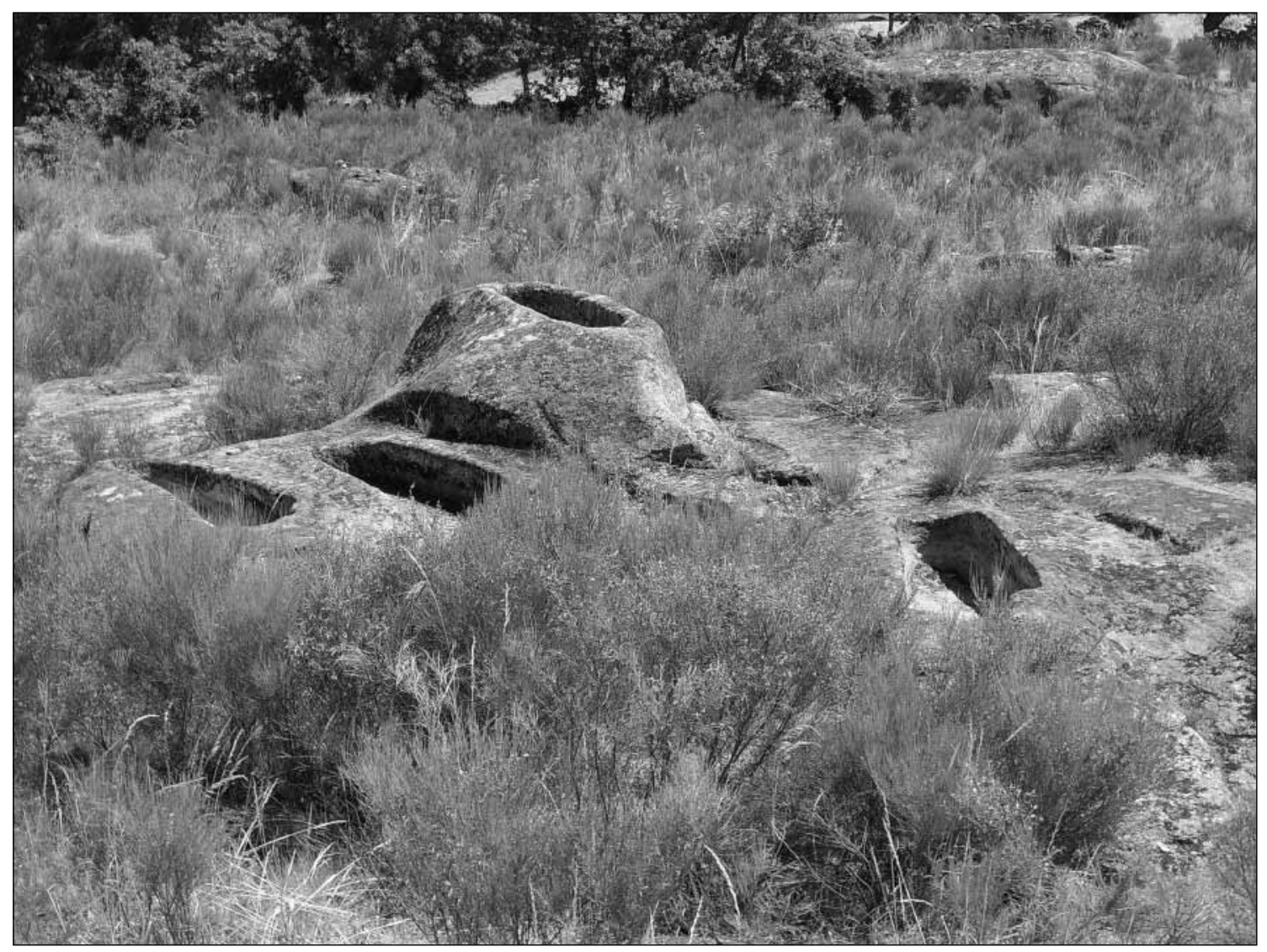

Fig. 13. Negrelhos (Vascoveiro): posible núcleo ordenado en torno a tumba de estatus 


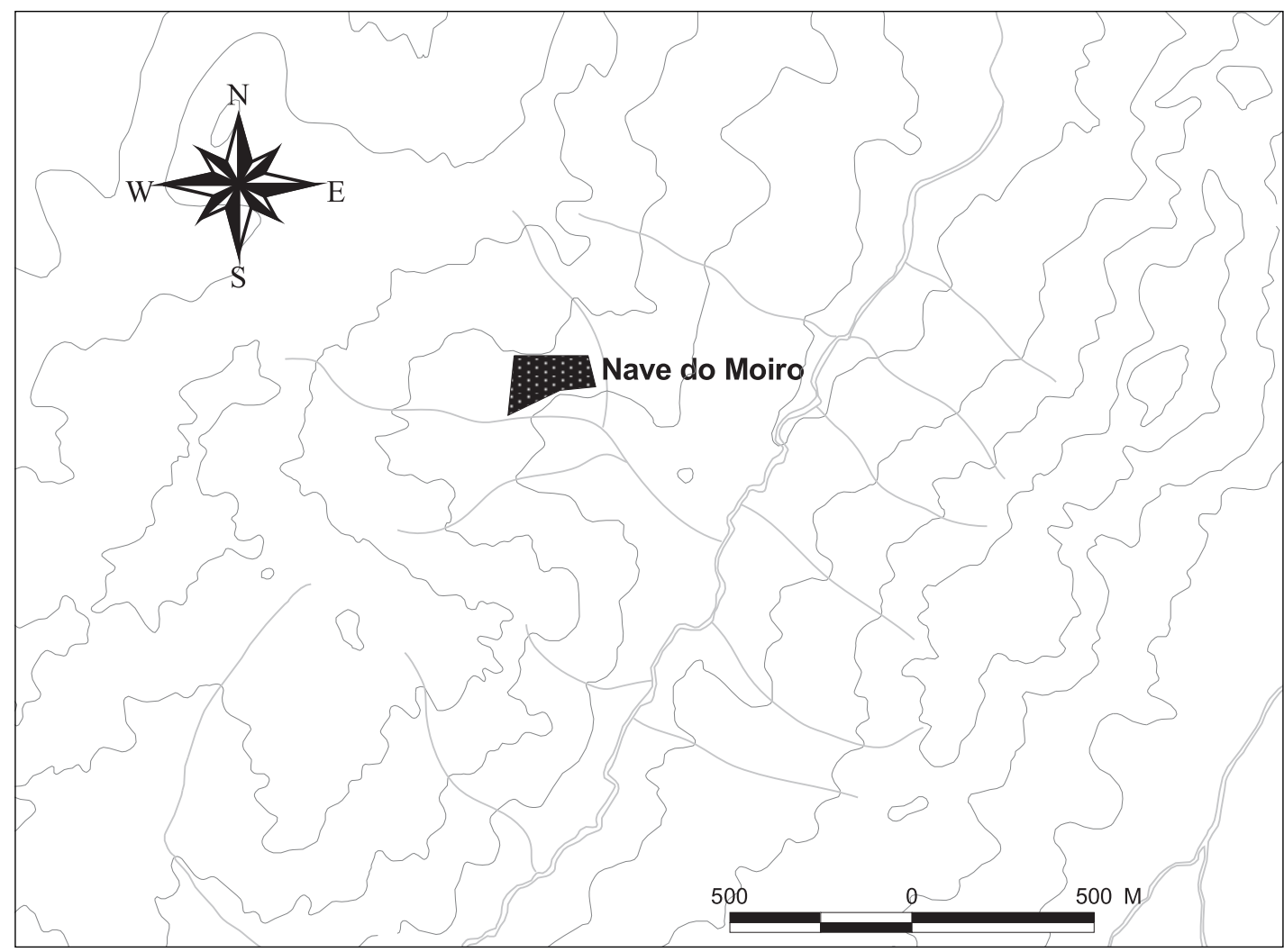

Fig. 14. Localización de la necrópolis de $\mathrm{N}$ ave do Moiro (Malpartida)

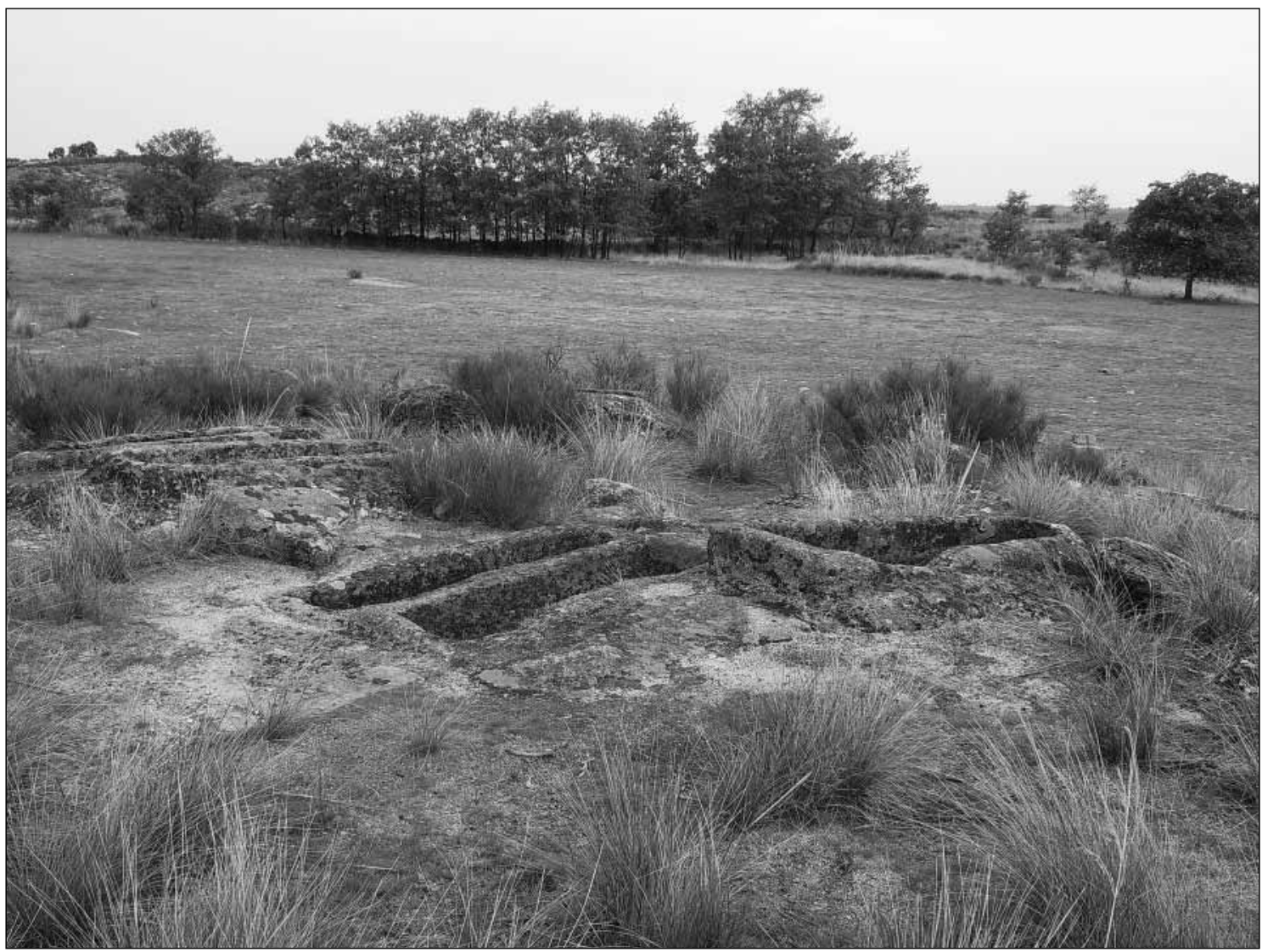

Fig. 15. Núcleo de tumbas y espacio de ribeira en $N$ ave do Moiro (Malpartida) 